\title{
How Hosts Taxonomy, Trophy, and Endosymbionts Shape Microbiome Diversity in Beetles
}

\author{
Michał Kolasa $^{1}$ (D) $\cdot$ Radosław Ścibior $^{2} \cdot$ Miłosz A. Mazur $^{3} \cdot$ Daniel Kubisz $^{1} \cdot$ Katarzyna Dudek $^{4} \cdot$ Łukasz Kajtoch $^{1}$
}

Received: 19 December 2018 / Accepted: 7 March 2019 / Published online: 27 March 2019

(C) The Author(s) 2019

\begin{abstract}
Bacterial communities play a crucial role in the biology, ecology, and evolution of multicellular organisms. In this research, the microbiome of 24 selected beetle species representing five families (Carabidae, Staphylinidae, Curculionidae, Chrysomelidae, Scarabaeidae) and three trophic guilds (carnivorous, herbivorous, detrivorous) was examined using 16S rDNA sequencing on the Illumina platform. The aim of the study was to compare diversity within and among species on various levels of organization, including evaluation of the impact of endosymbiotic bacteria. Collected data showed that beetles possess various bacterial communities and that microbiota of individuals of particular species hosts are intermixed. The most diverse microbiota were found in Carabidae and Scarabaeidae; the least diverse, in Staphylinidae. On higher organization levels, the diversity of bacteria was more dissimilar between families, while the most distinct with respect to their microbiomes were trophic guilds. Moreover, eight taxa of endosymbiotic bacteria were detected including common genera such as Wolbachia, Rickettsia, and Spiroplasma, as well as the rarely detected Cardinium, Arsenophonus, Buchnera, Sulcia, Regiella, and Serratia. There were no correlations among the abundance of the most common Wolbachia and Rickettsia; a finding that does not support the hypothesis that these bacteria occur interchangeably. The abundance of endosymbionts only weakly and negatively correlates with diversity of the whole microbiome in beetles. Overall, microbiome diversity was found to be more dependent on host phylogeny than on the abundance of endosymbionts. This is the first study in which bacteria diversity is compared between numerous species of beetles in a standardized manner.
\end{abstract}

Keywords Bacterial community $\cdot$ Host-microbe interactions $\cdot$ Coleoptera $\cdot$ Endosymbionts $\cdot$ Microbial ecology

\section{Introduction}

Multicellular organisms share an inextricable and mutualistic relationship with a large number of resident microorganisms, collectively known as the microbiota (microbiome) [1]. Nowadays, microbiome is considered one of the most important factors that shapes the life history of its hosts. Naturally, the best studied animal in the context of the relationship between microbiota and host is the human (e.g., [2]) and model organisms (e.g., [3-6]). In contrast, microbiome diversity and relations with hosts have rarely been investigated in the context of wild animals, but this is quickly changing thanks to the development of new sequencing technologies and their decreasing costs. Thus far, the majority of microbiome studies

Electronic supplementary material The online version of this article (https://doi.org/10.1007/s00248-019-01358-y) contains supplementary material, which is available to authorized users.

Michał Kolasa

michal.r.kolasa@gmail.com

1 Institute of Systematics and Evolution of Animals, Polish Academy of Sciences, Krakow, Poland

Institute of Biology, University of Opole, Opole, Poland

4 Molecular and Behavioral Ecology Group, Jagiellonian University, Krakow, Poland

2 Department of Zoology and Animal Ecology, University of Life Sciences in Lublin, Lublin, Poland 
in relation to hosts have been conducted with vertebrates (e.g., [7-11]). It is assumed that the complexity and diversity of the symbioses of bacteria and invertebrates (particularly insects) are lower than those associated with vertebrates [12]. Simultaneously, the influence of bacteria on insect hosts should be similar. It has been proven that some organisms may have a significant influence on the composition of hosts microbiota: parasites [13], symbionts [14], or endosymbionts [15]. While interaction between host and parasite or symbionts are well-studied and documented [16, 17], scientists have only begun to clarify the relationship with endosymbionts. One of the most thoroughly examined groups of microbes are endosymbiotic bacteria belonging to so-called male-killing bacteria [18]. Endosymbiotic bacteria are a specific group of organisms that are known first of all to influence host reproduction. Several intracellular bacteria are known to have such an impact on their hosts. The best known are two genera of $\alpha$-proteobacteria: Wolbachia and Rickettsia. Others, such as Spiroplasma (Mollicutes) and Cardinium (Bacteroidetes), are much less studied [19-22]. Wolbachia have been reported as being found in arthropods and filarial nematodes around the world [23, 24]. Rickettsia also seem to be a common bacterial symbiont of arthropods [25]; they can manipulate host reproduction in arthropods through various mechanisms (see [18, 26] for the review). Moreover, Wolbachia may be an obligatory bacteriocyte-associated nutritional mutualist [27], which highlights a previously unknown aspect of the parasitismmutualism evolutionary continuum.

Although we have begun to better understand the importance and function of microbiota, the relationship between the diversity of microbiome and traits (both phylogenetic and ecologic) of their host remain understudied topics. Due to richness of species, well-studied taxonomic relationships, and a relatively low complexity level of microbiota, insects seemed to be the perfect choice for such studies. Actually, the relationship between host taxonomy, trophism, and microbiota has already been the subject of meta-analysis [28]. Nonetheless, the latter work summarized previous studies, which caused numerous limitations. The study did not allow for a full elaboration of the topic. First of all, because Colman's work was based on meta-analysis, examined data could not be standardized. Secondly, that unintended sampling caused an overrepresentation of insect species from some orders (e.g., Hymenoptera); also, some trophic guilds were highly underrepresented (e.g., carnivorous and herbivorous). For example, coleopterans were included as representatives of Cerambycidae, Buprestidae and Scolytinae (xylophagous), Carabidae (carnivorous), and Tenebrionidae (omnivorous), but most of these groups were represented by single species. Third, the number of examined specimens per species was various but generally too low for proper estimation of microbiome diversity. Finally, this study was done before 2012, the period in which capabilities of molecular tools were limited and therefore, all bacteria sequences were generated using traditional Sanger sequencing in conjunction with molecular cloning. This could cause several biases, mainly leading to underrepresentation of microbiome diversities. An interesting study by Yun et al. [29] examines microbiome of more than 300 insect species with use of next-generation sequencing (NGS). This study focused on a wide coverage of hosts with very low sampling per species (mostly single specimens were used), which prevented any intraspecific analyses and allowed for comparison of microbiomes only on high taxonomic levels. Studies by Colman et al. [28] and Yun et al. [29] develop interesting topics, but to fully address relations between microbiota and their insect hosts, more detailed and restricted research are needed. For the purposes of this study, beetles were selected: this group gives numerous opportunities to study various relations between microbiome and hosts of various phylogenetic relations and ecological affinity.

Beetles are the most species-rich and diversified order of insects in the world, including approximately nearly 400,000 known species [30]. They can be found in most terrestrial and freshwater habitats. Members of Coleoptera belong to all major trophic guilds known in animals. Despite such complexity and diversity, knowledge of microbiota in this group of insects is limited. So far, microbiome has only been examined in single species belonging to one of the trophic guilds: detritivores-coprophages [31,32], scavengers [33], xylophages or cambiophages [34-38], herbivores [39-42], as well as carnivores [43-45]. Complex analyses concerning diversity of microbiota in relation to beetle phylogeny (taxonomy) and ecology (e.g., trophy) has yet to be conducted. The only well-studied bacteria of beetles are endosymbiotic "male-killing" bacteria, particularly Wolbachia [22], which additionally makes Coleoptera a good group to choose for microbiome studies.

The aim of this study was to use NGS to characterize the microbiome composition of 24 beetle species belonging to three trophic guilds (detritivorous, herbivorous, carnivorous) and five families (Carabidae, Staphylinidae, Chrysomelidae, Curculionidae, Scarabaeidae). This part aimed to verify whether microbiota composition is more similar within the species than between hosts (H1) and was assessed on two levels: that microbiome is similar in beetles belonging to the same taxonomic unit (family) (H2) or trophic guild (H3). Secondly, we established whether infection by endosymbionts (mainly Wolbachia and Rickettsia) could influence composition of microbiome to verify the hypothesis that the presence of endosymbionts correlates with microbiota diversity (that an increased number of endosymbionts decreases number of other bacteria) (H4). Additionally, we checked if an abundance of endosymbionts are negatively correlated with each other in order to verify the hypothesis that particular genera of these bacteria occur interchangeably (H5). 


\section{Materials and Methods}

\section{Species Selection and Sampling}

For the purposes of this study, 24 species of beetles were selected. Beetle species were chosen based on the following criteria: (i) taxonomic position, (ii) trophic assignment, and (iii) status of endosymbiotic bacterial infection (based on previous studies). The first and second categories were partially related, as in beetles most taxonomic units (e.g., families or genera) are strictly associated with a particular diet and foraging mode (e.g., the majority of Carabidae are carnivorous). We decided to analyze three basic trophic guilds known in beetles, that is: (1) carnivorous, (2) herbivorous, and (3) detrivorous (specifically coprophagous) species. Among carnivorous, members of two groups were selected: Carabidae (ground beetles) and Staphylinidae (rove beetles). Among herbivorous species, two groups were also selected: Curculionidae (weevils) and Chrysomelidae (leaf beetles). Finally, all detrivorous species were recruited from Scarabaeidae (dung beetles). To omit biases, which could be potentially caused by different habitat preferences, foraging, or distribution of sampled species, selected beetles (within trophic guilds and taxonomic units) were selected from species of similar habitat and food preferences. For example, all carnivorous (Carabidae and Staphylinidae) were required from riparian beetles, all herbivorous (Curculionidae and Chrysomelidae) from grassland species, and all detrivorous (Scarabaeidae) from coprophagous species associated with wild and domestic mammals. Considering restrictions of next-generation sequencing, the total number of specimens planned to be analyzed (200) were divided between taxonomic groups (families) and trophic guilds. In species selection, the third criterion was also included: infection status by endosymbiotic bacteria, particularly Wolbachia. Infection status was based on previous research with use of genotyping by multilocus sequence typing [46] (details in: [47-50]). Half of the species from each group (each family and each trophic guild) was selected to be infected by Wolbachia; the second half had to be uninfected. Finally, 24 beetle species were selected. For 16 species (four ground beetles, four rove beetles, four weevils and four leaf beetles), 10 specimens per species were randomly selected from the collection of beetles from Europe preserved for molecular studies in the Department of Collections Institute of Systematics and Evolution of Animals, Polish Academy of Sciences in Krakow. The remaining eight species of dung beetles were sampled on five random specimens each (the lower number of specimens was due to fewer sampling of beetles belonged to this group (difficulties in sampling larger number of specimens in the field). Details related to sampling (taxonomic affinity, trophy assignment and Wolbachia infection status of selected beetle species with number of analyzed specimens) are presented in Table 1.

\section{DNA Isolation and Sequencing}

DNA was isolated from 200 specimens belonging to 24 species of coleopterans using The Wizard Genomic DNA Purification Kit (Promega). Prior to isolation, all beetle specimens were surface-bleached in distilled water. Isolation was conducted in blocks with two blank samples for each block to rule out contamination with bacterial DNA. DNA was used within a few hours after isolation and then stored at $-20^{\circ} \mathrm{C}$. All laboratory procedures were carried out in accordance with the Earth Microbial Project protocol (http:// www.earthmicrobiome.org/protocols-and-standards/16s/). The V4 region of the 16S SSU rDNA was amplified with 515 FB-806RB primer pair: forward: G T G Y C A G C M G C C G C G G TA A ; reverse : GGACTACNVGGGTWTCTAAT [51] with the addition of an index sequence unique for each specimen and Illumina adaptor. PCR was performed using the following steps: $94{ }^{\circ} \mathrm{C}$ for $3 \mathrm{~min}$ and 35 cycles of $94{ }^{\circ} \mathrm{C}$ for $45 \mathrm{~s}, 50{ }^{\circ} \mathrm{C}$ for $60 \mathrm{~s}$, and $72{ }^{\circ} \mathrm{C}$ for $90 \mathrm{~s}$ with a final extension of $72{ }^{\circ} \mathrm{C}$ for 10 min. Blank samples were run on agarose gel along with samples with DNA isolates. Since blank samples did not show any products on the gel, they were excluded from further procedures. PCRs with DNA of all samples were repeated three times to avoid batch effect [52]. Subsequently, three samples per specimen were pulled together and run on a $2 \%$ agarose gel with a 100-bp ladder to check for amplification efficacy. Samples were pooled equimolarly based on the intensity of the bands. The next pool of samples were run on gel through electrophoresis. Afterward, bands of desired length were cut out from the gel and cleaned with the Zymoclean Gel DNA Recovery Kit (Zymo). Concentration of the library was measured with Qubit and sequenced with Illumina MiSeq platform (600 cycles) using the MiSeq Reagent Kit v3.

\section{Pre-processing and Data Analysis}

Demultiplexed paired-end fastq files generated by Illumina and a mapping file were used as input files. Sequences were pre-processed, quality filtered, and analyzed using QIIME2 version 2018.2 [53]. The DADA2 software package within QIIME2 was used for modeling and correcting Illumina sequenced fastq files including the removal of chimeras using the "consensus" method. Due to a drop of quality scores sequences were truncated 40 bases from forward and 70 bases from reverse reads (with Phred score 25 as a threshold). For taxa comparison, relative abundances based on all obtained reads were used. The QIIME2 q2-feature-classifier plugin were used. The Naiive Bayes classifier that was trained on the SILVA132 99\% OTUs full-length sequence database and subsequent sequences from our dataset were assigned to OTUs from SILVA database with similarity on the $99 \%$ level. To view the taxonomic composition of the samples, the 


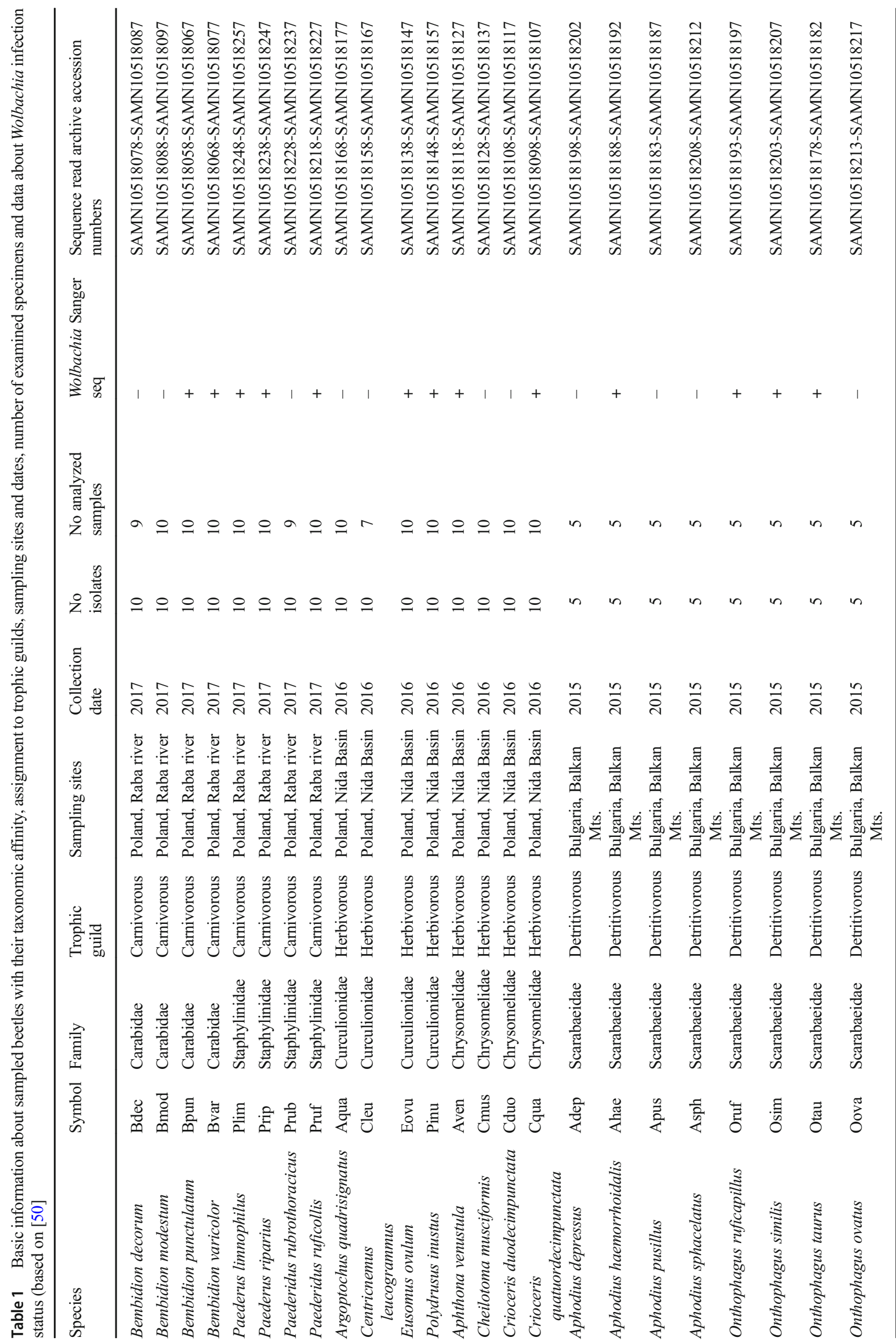


QIIME2 taxa bar plot command was used. Next, all unassigned sequences were excluded from further analysis. Alpha and beta-diversity analyses were performed with the q2-diversity plugin in QIIME2 at a sampling depth of 2000, which was based on rarefaction curve. Alpha diversity was calculated by Shannon's diversity index (hereafter Shannon), observed OTUs (hereafter OTU), Pielou's measure of species evenness (hereafter Pielou), and Faith's phylogenetic diversity (hereafter Faith). For description of the particular bacteria present in higher number of reads in analyzed beetles, bacterial OTUs were pulled to the level of genus (or any higher taxonomic rank if lower classification was not possible), e.g., all OTU classified as Wolbachia were considered jointly, etc. Beta diversity was estimated with use of unweighted UniFrac (hereafter uwUniFrac) and weighted UniFrac (hereafter wUniFrac), Bray-Curtis distance (hereafter Bray-Curtis), and Jaccard distance (hereafter Jaccard). Basic statistics showing means, ranges and standard deviations of these indices were calculated for all examined species separately, as well as for families and trophic guilds. Differences in alpha diversity indices between groups of beetles on three levels-(i) among species from particular family, (ii) among families, and (iii) among trophic guilds - were statistically assessed with use of Kruskal-Wallis test (for which all the assumptions have been verified), which was next visualized in QIIME2. Beta diversity was compared between groups using principal coordinates analysis (PCoA) with pairwise comparisons (PERMANOVA) and visualized with the emperor plugin in QIIME2. The bacterial communities associated with three levels of grouping were ordinated, according to microbiome composition similarity, using the distance-based non-metric multi-dimensional scaling (NMDS) [54]. The differences among the bacterial communities associated with three levels of differentiation (species, family, trophy) were estimated by a nonparametric one-way analysis of similarity (ANOSIM) [55].

Moreover, endosymbionts abundance was correlated with modified alpha diversity indices. Abundance was expressed by number of reads found for Wolbachia and Rickettsia, as only these taxa were found to be numerous in obtained microbiome sequences. To avoid biases caused by selfexplanation of microbiome diversity by the endosymbiont prevalence parameter (as endosymbiotic bacteria constituted a large part of bacteria in many samples), all reads belonging to Wolbachia and Rickettsia were removed from datasets before calculation of modified alpha diversity indices in this step of analyses. Additionally, correlations between number of reads found for all identified endosymbiotic bacteria were also calculated. Abovementioned correlation were also repeated on only presence-absence data of particular endosymbiotic taxa.

Due to the simplicity of analyzed dataset of beetle hosts ( 24 species from only five families and three trophic guilds), a high correlation between these three levels of sample assignment (species, family, and trophy) was observed ( Rho $=0.98$ between species and family, Rho $=0.95$ between family and trophy, and Rho $=0.93$ between species and trophy). This ruled out the possibility of any multivariate analyses on these three states of host assignment. However, the effects of host phylogenetic relations and abundance of endosymbionts on overall diversity of bacteria was estimated with use of generalized linear models (GLMs). Host phylogenetic relations were expressed by use of genetic distances (adopting Kimura-two parameters as the substitution model; [56] calculated from sequences of cytochrome oxidase gene, subunit I (coxI) obtained from beetles (data from [50]), hereafter DISTANCE. Endosymbiotic bacteria prevalence was measured as a summarized number of $16 \mathrm{~S}$ reads assigned to any bacteria from genera known as to be endosymbiotic for insects (see "Results" for details), hereafter ENDOSYMBIONTS. Explained variable (microbiome diversity) was taken from QIIME2 calculations of alpha diversity (four separate GLMs were analyzed for Shannon, OTUs, Pielou, and Faith). To avoid biases caused by self-explanation of microbiome diversity by endosymbiont (this concern most abundant Wolbachia and Rickettsia) prevalence parameter (as endosymbiotic bacteria constituted a large part of bacteria in many samples), all reads belonged to endosymbiotic bacteria were removed from dataset before calculation of alpha diversity indices. Models were next ranged according to Akaike information criterion (AIC) and AIC weights $(w)$ following recommendations of Burnham and Andreson [57]. Statistical analyses (except these from QIIME2) were executed in R package [58].

\section{Results}

\section{General Characteristic of Microbiomes}

After quality control, we obtained a total of $9,320,053$ demultiplexed sequences from 200 specimens of 24 beetle species belonging to five families and three trophic guilds (Suppl. Table 1). The mean sequence frequency was 46,600.3 per specimen (median 31,316.0, min 0.0, max $368,452.0$ per specimen). Five specimens (one Paederidus rubrothoracicus, one Bembidion decorum, and three Centricnemus leucogrammus) were excluded in this process.

After rarefaction on average, for most of specimens, 2000 4000 Illumina reads of $16 \mathrm{~S}$ sequences were obtained; however, these values varied greatly (Table 2). The number of OTUs obtained from collected reads also varied greatly between particular beetles, but on average, 80-140 OTUs were observed per species (Table 2).

Due to the high number of bacteria taxons within samples (Fig. 1, Suppl. Fig. 1), the descriptive part of results was focused on only bacteria, which OTUs were found in abundance (for at least one half of individuals from particular host 
Table 2 Basic characteristics of collected data (sequences of bacteria) obtained from examined beetles. $N$ reads $=$ number of $16 \mathrm{~S}$ rDNA reads; $\mathrm{OTU}=$ number of operational taxonomic units

\begin{tabular}{|c|c|c|c|c|c|c|c|c|}
\hline \multirow[t]{2}{*}{ Hosts } & \multicolumn{4}{|l|}{$N$ reads } & \multicolumn{4}{|l|}{ OTU } \\
\hline & Mean & Min & Max & $\mathrm{SD}$ & Mean & Min & Max & SD \\
\hline \multicolumn{9}{|l|}{ Species } \\
\hline Bembidion decorum & 41,535 & 800 & 117,373 & 37,915 & 195 & 10 & 491 & 148 \\
\hline Bembidion modestum & 34,446 & 16,651 & 65,357 & 15,356 & 108 & 12 & 189 & 64 \\
\hline Bembidion punctulatum & 33,125 & 12,089 & 140,466 & 38,979 & 164 & 67 & 285 & 71 \\
\hline Bembidion varicolor & 22,052 & 11,885 & 48,390 & 12,678 & 165 & 38 & 398 & 122 \\
\hline Paederus limnophilus & 91,999 & 63,990 & 127,029 & 21,732 & 46 & 11 & 173 & 60 \\
\hline Paederus riparius & 30,512 & 11,733 & 47,180 & 11,340 & 29 & 7 & 71 & 24 \\
\hline Paederidus rubrothoracicus & 31,033 & 13,231 & 54,406 & 14,539 & 27 & 8 & 58 & 16 \\
\hline Paederidus ruficollis & 30,136 & 16,767 & 53,419 & 11,765 & 67 & 9 & 196 & 67 \\
\hline Aphthona venustula & 33,882 & 2900 & 73,418 & 20,064 & 121 & 14 & 335 & 112 \\
\hline Crioceris duodecimpunctata & 21,593 & 8003 & 34,031 & 9010 & 153 & 72 & 325 & 89 \\
\hline $\begin{array}{l}\text { Crioceris } \\
\quad \text { quatuordecimpunctata }\end{array}$ & 37,369 & 18,832 & 106,314 & 25,269 & 45 & 7 & 343 & 105 \\
\hline Cheilotoma musciformis & 53,582 & 21,661 & 117,717 & 36,263 & 17 & 5 & 40 & 11 \\
\hline Argoptochus quadrisignatus & 35,238 & 13,546 & 79,716 & 18,816 & 36 & 9 & 79 & 24 \\
\hline Centricnemus leucogrammus & 5805 & 963 & 17,373 & 5693 & 73 & 29 & 124 & 31 \\
\hline Eusomus ovulum & 53,938 & 17,797 & 105,669 & 24,506 & 108 & 5 & 348 & 122 \\
\hline Polydrusus inustus & 26,859 & 6225 & 72,234 & 18,471 & 34 & 6 & 123 & 36 \\
\hline Aphodius depressus & 226,814 & 135,860 & 368,452 & 86,183 & 207 & 150 & 270 & 50 \\
\hline Aphodius haemorrhoidalis & 133,394 & 92,578 & 210,402 & 44,863 & 211 & 167 & 262 & 42 \\
\hline Aphodius pusillus & 36,966 & 14,277 & 80,054 & 27,131 & 149 & 79 & 221 & 57 \\
\hline Aphodius sphacelatus & 13,764 & 5041 & 22,026 & 6798 & 53 & 32 & 74 & 16 \\
\hline Onthophagus ruficapillus & 95,836 & 85,436 & 118,802 & 14,673 & 173 & 77 & 219 & 60 \\
\hline Onthophagus similis & 113,431 & 71,700 & 145,375 & 34,800 & 157 & 65 & 199 & 56 \\
\hline Onthophagus taurus & 68,911 & 53,096 & 79,916 & 9779 & 201 & 156 & 237 & 35 \\
\hline Onthophagus ovatus & 16,059 & 11,504 & 24,406 & 5195 & 107 & 81 & 139 & 26 \\
\hline \multicolumn{9}{|l|}{ Families } \\
\hline Carabidae & 32,789 & 800 & 140,466 & 28,702 & 158 & 10 & 491 & 108 \\
\hline Staphylinidae & 46,302 & 11,733 & 127,029 & 30,963 & 43 & 7 & 196 & 49 \\
\hline Curculionidae & 31,092 & 963 & 105,669 & 24,734 & 63 & 5 & 348 & 72 \\
\hline Chrysomelidae & 36,606 & 2900 & 117,717 & 26,385 & 84 & 5 & 343 & 102 \\
\hline Scarabaeidae & 88,147 & 5041 & 368,452 & 76,049 & 157 & 32 & 270 & 66 \\
\hline \multicolumn{9}{|l|}{ Trophic guilds } \\
\hline Carnivorous & 86,782 & 5041 & 368,452 & 75,599 & 154 & 31 & 270 & 68 \\
\hline Herbivorous & 33,906 & 963 & 117,717 & 25,735 & 74 & 5 & 348 & 89 \\
\hline Detrivorous & 39,460 & 800 & 140,466 & 30,417 & 101 & 7 & 491 & 102 \\
\hline
\end{tabular}

species) higher than 5\% (Suppl. Table 2). Occurrence of endosymbiotic bacteria (particularly Wolbachia, Rickettsia, and Spiroplasma) is described in following chapter; the descriptions below concern only other bacterial taxa.

Regarding ground beetles, more than $5 \%$ of the reads were found for one OTU of Enterococcus (Bacilli) in Bembidion punctulatum, one OTU from family Comamonadaceae (Betaproteobacteria) in B. punctulatum, two OTUs from Enterobacteriaceae and two OTUs from Pseudomonas (both Gammaproteobacteria) in B. punctulatum, one Orbus OTU
(Gammaproteobacteria) in all Bembidion species and unidentified Proteobacteria OTU in B. modestum (Suppl. Table 2).

Among rove beetles, one OTU of Flavobacteriaceae (Flavobacteriia) was abundant in Paederus ruficollis, one Leptotrichiaceae OTU (Fusobacteriia) was found in $P$. rubrothoracicus, two OTUs of Enterobacteriaceae (Gammaproteobacteria) were present in P. rubrothoracicus, one OTU from order Pseudomonadales (both Gammaproteobacteria) infected all rove beetle species (Suppl. Table 2). 
others

- Planococcaceae: unknown

Enterococcaceae: unknown

Aeromonadaceae: Aeromonas

Orbaceae: Orbus

- Pseudomonadales: unknown

Gammaproteobacteria: unknown
Flavobacteriaceae: Empedobacter — Flavobacteriaceae: unknown - Planococcaceae: Solibacillus Carnobacteriaceae: Carnobacterium - Carnobacteriaceae: unknown - Enterococcaceae: Enterococcus Ruminococcaceae: unknown

- Enterobacteriaceae:

Escherichia-Shigella

Pasteurellaceae: Pasteurella

Sphingomonadaceae: Sphingomonas

Comamonadaceae: unknown

Enterobacteriaceae: unknown

Moraxellaceae: Acinetobacter Pseudomonas

Anaplasmataceae: Wolbachia Rickettsiaceae: Rickettsia
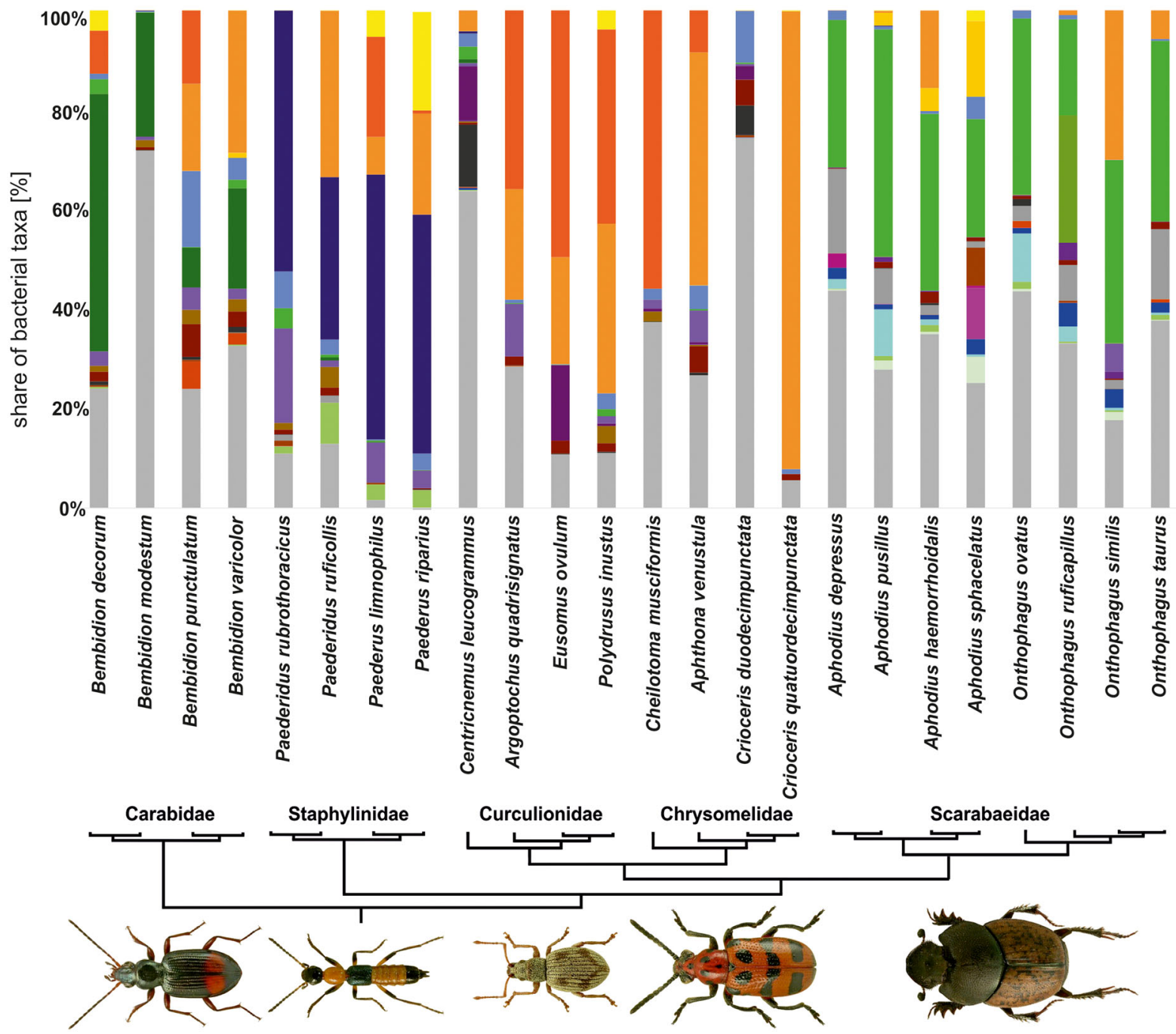

Fig. 1 The plot of the relative share of bacteria in examined specimens of 24 species of beetles showed in relation to a simplified phylogenetic tree of examined beetles. Shown only bacterial operational taxonomic units, which relative frequencies higher than $5 \%$ and found in more than half of examined individuals in any of infected host. Photographs of exemplary

infected beetle hosts were reprinted from ICONOGRAPHIA COLEOPTERORUM POLONIAE under a CC BY license, with permission (@ Copyright. by Prof. Lech Borowiec, Wrocław 20072018, Department of Biodiversity and Evolutionary Taxonomy, University of Wroclaw, Poland)

In weevils, one Sphingomonas OTU (Alphaproteobacteria) was found in C. leucogrammus, Pantoea OTU (Gammaproteobacteria) was numerous in C. leucogrammus and Eusomus ovulum, and one OTU from family Enterobacteriaceae (Gammaproteobacteria) was found in Argoptochus quadrisignatus (Suppl. Table 2).

Regarding leaf beetles, one OTU of Sphingomonas (Alphaproteobacteria) was found in Crioceris duodecimpunctata, Comamonadaceae OTU (Betaproteobacteria) was present in Aphthona venustula and C. duodecimpunctata, and Enterobacteriaceae OTU
(Gammaproteobacteria) was found in A. venustula (Suppl. Table 2).

Among dung beetles, in all eight species, three Acinetobacter OTUs (Gammaproteobacteria) dominated. Moreover, the following bacteria reached 5\% in some hosts: Empedobacter OTU (Flavobacteriia) in Aphodius sphacelatus, Solibacillus OTU (Bacilli) in A. pusillus and Onthophagus ovatus, Carnobacterium OTU (Bacilli) in A. sphacelatus, Enterococcaceae OTU (Bacilli) in A. sphacelatus, Ruminococcaceae OTU (Clostridia) in A. depressus and O. taurus, Neisseriaceae OTU 
(Betaproteobacteria) in A. sphacelatus, Enterobacteriaceae OTU (Gammaproteobacteria) in O. similis, Pasteurella OTU (Gammaproteobacteria) in O. ruficapillus and unidentified Gammaproteobacteria OTU in A. sphacelatus (Suppl. Table 2).

\section{Alpha Diversity}

Microbiome alpha diversity differed significantly among samples in all three levels of grouping (species, family, and trophic guild), and it was observed for all four metrics (OTU, Shannon, Faith, and Pielou) (Table 3, Suppl. Table 3a, Fig. 2, Suppl. Fig. 2).

Among ground beetles, the highest microbiome diversity was found in $B$. decorum and B. punctulatum and lower in B. modestum and Bembidion varicolor. P. ruficollis had the highest microbiome diversity among all rove beetles with other three taxa of similarly lower metrics of diversity. In weevils, C. leucogrammus possessed most diverse bacteria, followed by E. ovulum, Polydrusus inustus, and A. quadrisignatus. Two sister species of Crioceris leaf beetles had totally different diversity of microbiome with $C$. duodecimpunctata of much higher diversity of bacteria. Also, A. venustula had much more diverse microbiome than Cheilotoma musciformis. Among dung beetles, most species were characterized by high diversity of bacteria, and only A. sphacelatus had very low microbiome diversity (Table 2, Suppl. Table 3a, Suppl. Fig. 2).

On the level of the beetle family, there were substantial differences in diversity of bacteria. Overall, the highest diversity of microbiome was observed for Scarabaeidae and next for Carabidae. Lower diversity was found for Chrysomelidae and Curculionidae and the lowest for Staphylinidae (Table 2, Suppl. Table 3a, Fig. 2).

Obviously, a similar pattern was observed for beetles grouped into trophic guilds, with highest diversity of bacteria found for detritivores and lowest diversities observed in herbivores and carnivores (the latter was caused by joint measuring of diversity of bacteria rich ground beetles and bacteria of poor rove beetles) (Table 2, Suppl. Table 3a, Fig. 2).

\section{Beta Diversity}

All four metrics of beta diversity (Bray-Curtis, Jaccard, wUniFrac, and uwUniFrac) resulted in consistent results. However, distances between beetle hosts were found to be different depending on the level of species grouping: species, families or trophic guilds (Table 3, Suppl. Table 3b, Fig. 3, Suppl. Figs. 3, 4).

Regarding microbiome similarity between particular species of beetles, most hosts belonging to the same taxa did not cluster into distant groups from other members of either the same family or trophic guild. Microbiomes found in individuals of beetles generally were intermixed and only rarely did some beetle species separate from others (Suppl. Table 3b, Suppl. Fig. 3).

In Carabidae only B. varicolor formed a separate unit; however, single individuals of this species seemed to have microbiome more similar to B. decorum or B. punctulatum. Among Staphylinidae and Curculionidae, no species formed distinct units in respect to their microbiota. In Chrysomelidae, 8 out of 10 specimens of Crioceris quatuordecimpunctata were found to be weakly different. Also, in Scarabaeidae, four out of five specimens of $A$. sphacelatus were separated from all other specimens from this family (Suppl. Table 3b, Suppl. Fig. 3).

If considering trophic guilds, no beetle species formed clustered separately in carnivorous, herbivorous or detrivorous (Suppl. Table 3b, Suppl. Fig. 3).

Quite opposite patterns were found when analyzing beetles in groups. On the level of families (Table 3, Suppl. Table 3b, Fig. 3, Suppl. Fig. 4), the most distinct microbiome was found

Table 3 Results of statistical comparison of microbiome alpha diversity metrics (Kruskal-Wallis test) and beta diversity metrics (PERMANOVA) calculated on three levels: beetle species, families, and trophic guilds

\begin{tabular}{|c|c|c|c|c|c|c|c|c|}
\hline \multicolumn{9}{|l|}{ Alpha diversity } \\
\hline \multirow[t]{2}{*}{ Kruskal-Wallis test } & \multicolumn{2}{|l|}{ OTUs } & \multicolumn{2}{|l|}{ Shannon } & \multicolumn{2}{|l|}{ Faith } & \multicolumn{2}{|l|}{ Pielou } \\
\hline & $H$ & $p$ value & $H$ & $p$ value & $H$ & $p$ value & $H$ & $p$ value \\
\hline Species & 123.03 & $<0.001$ & 115.73 & $<0.001$ & 118.85 & $<0.001$ & 93.56 & $<0.001$ \\
\hline Family & 79.67 & $<0.001$ & 74.10 & $<0.001$ & 71.68 & $<0.001$ & 54.53 & $<0.001$ \\
\hline Trophism & 45.17 & $<0.001$ & 46.41 & $<0.001$ & 32.99 & $<0.001$ & 38.45 & $<0.001$ \\
\hline \multicolumn{9}{|l|}{ Beta diversity } \\
\hline \multirow[t]{2}{*}{ PERMANOVA } & \multicolumn{2}{|l|}{ Bray-Curtis } & \multicolumn{2}{|l|}{ Jaccard } & \multicolumn{2}{|c|}{ Weighted UniFrac } & \multicolumn{2}{|c|}{ Unweighted UniFrac } \\
\hline & pseudo- $F$ & $p$ value & Pseudo- $F$ & $p$ value & Pseudo- $F$ & $p$ value & Pseudo- $F$ & $p$ value \\
\hline Species & 8.50 & 0.001 & 3.64 & 0.001 & 9.82 & 0.001 & 5.92 & 0.001 \\
\hline Family & 14.15 & 0.001 & 6.89 & 0.001 & 16.77 & 0.001 & 15.45 & 0.001 \\
\hline Trophism & $2,714,453.00$ & 0.001 & 7.49 & 0.001 & 20.56 & 0.001 & 20.25 & 0.001 \\
\hline
\end{tabular}



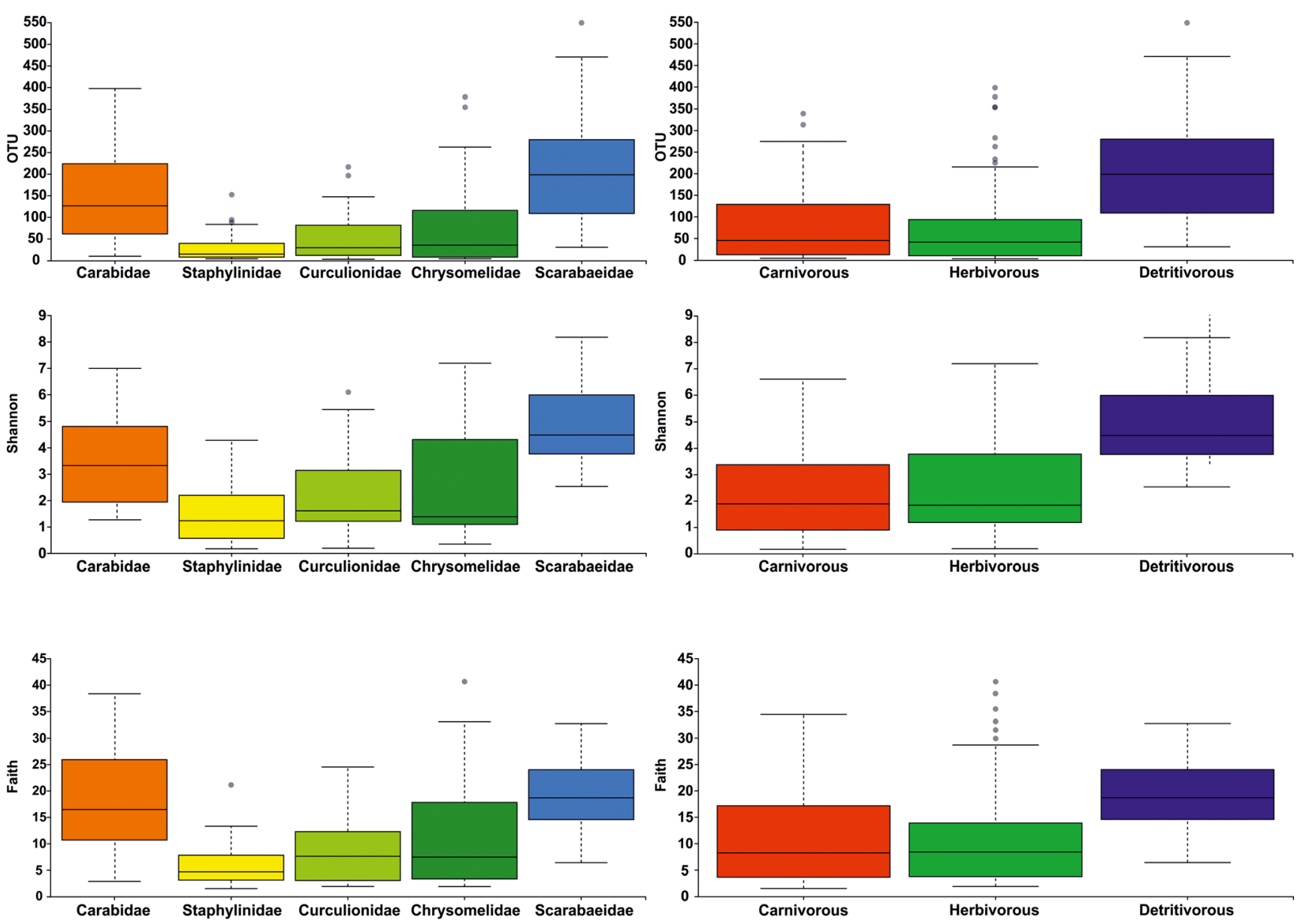

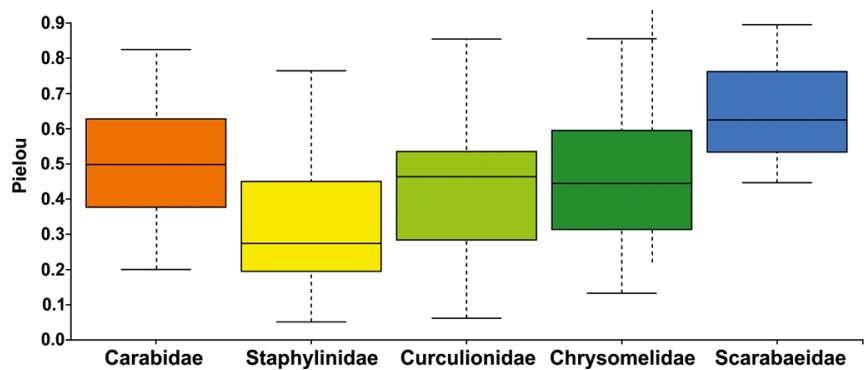

Fig. 2 Box plots of microbiome alpha diversity metrics (observed operational taxonomic units = OTU, Shannon's diversity index = Shannon, Faith's Phylogenetic Diversity = Faith, and Pielou's measure

to have dung beetles. Also, ground beetles and rove beetles formed partially separate groups with some overlap between species from these two groups. The only exceptions seemed to be Curculionidae and Chrysomelidae, members of which intermixed in respect to distinctiveness of their microbiota.

The abovementioned patterns resulted in much more visible distinctiveness of microbiomes found in hosts belonging to particular trophic guilds (Table 3, Suppl. Table 3b, Fig. 3. Suppl. Fig. 4). All three guilds (carnivorous, herbivorous and detrivorous) formed separate groups, with detrivorous most

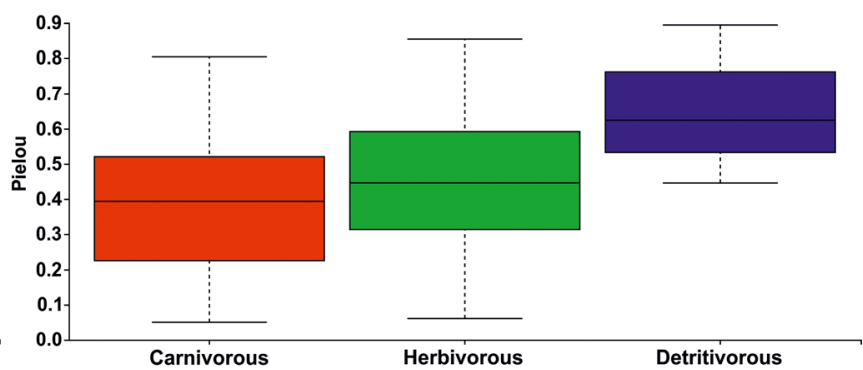

of species evenness $=$ Pielou) presented for beetles from selected families (left panel) and trophic guilds (right panel)

distant to all others. ANOSIM revealed significant differences of microbiome similarities on all three levels of grouping (ANOSIM $R=0.837, P=0.001$ for species; $R=0.693, P=$ 0.001 for families and $R=0.590, P=0.001$ for trophic guilds). This was also supported by NMDS plots, which show that microbiome of beetles from particular trophic guilds and families are generally different with some exceptions (e.g., weevils and leaf beetles; Fig. 4). Less obvious pattern was observed for species level, as numerous beetles overlapped in NMDS plot (Supp. Fig. 5). 
Family

Carabidae

Staphylinidae

Curculionidae

Chrysomelidae

Scarabaeidae
Trophy

Carnivorous

Herbivorous

Detritivorous

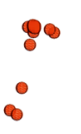

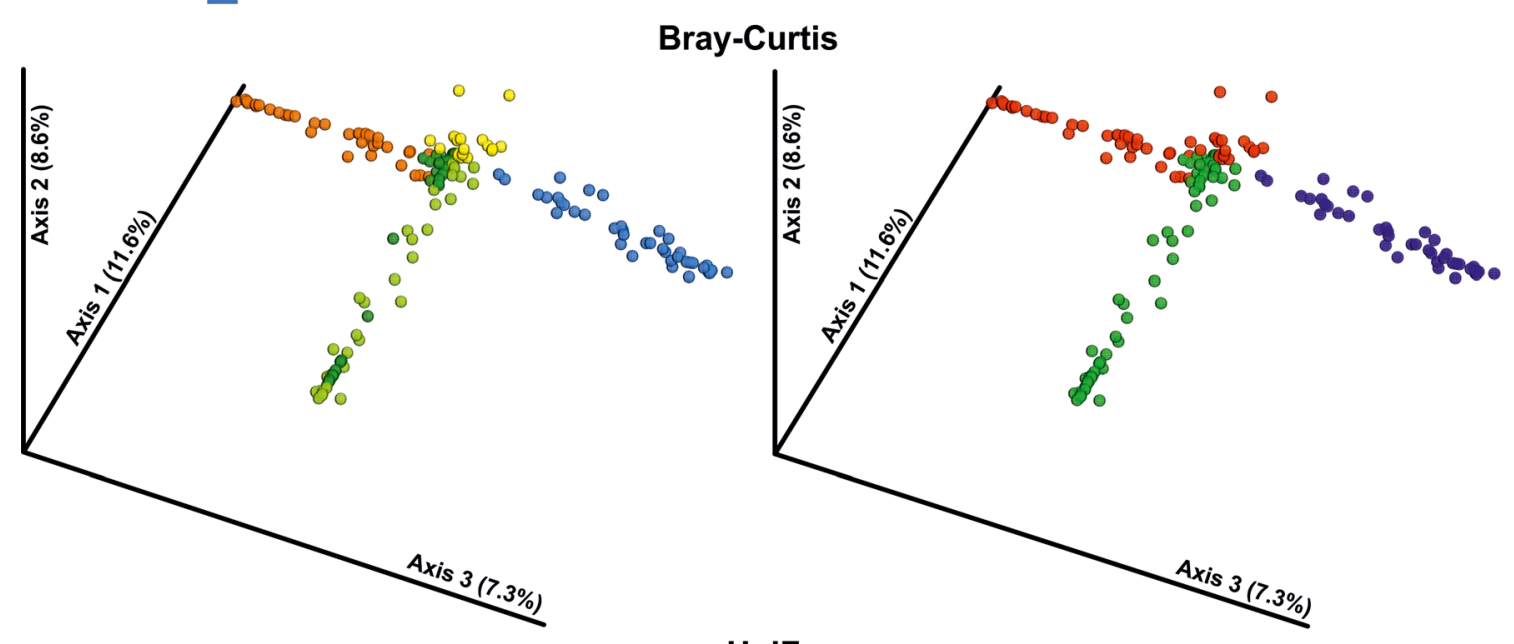

uwUniFrac

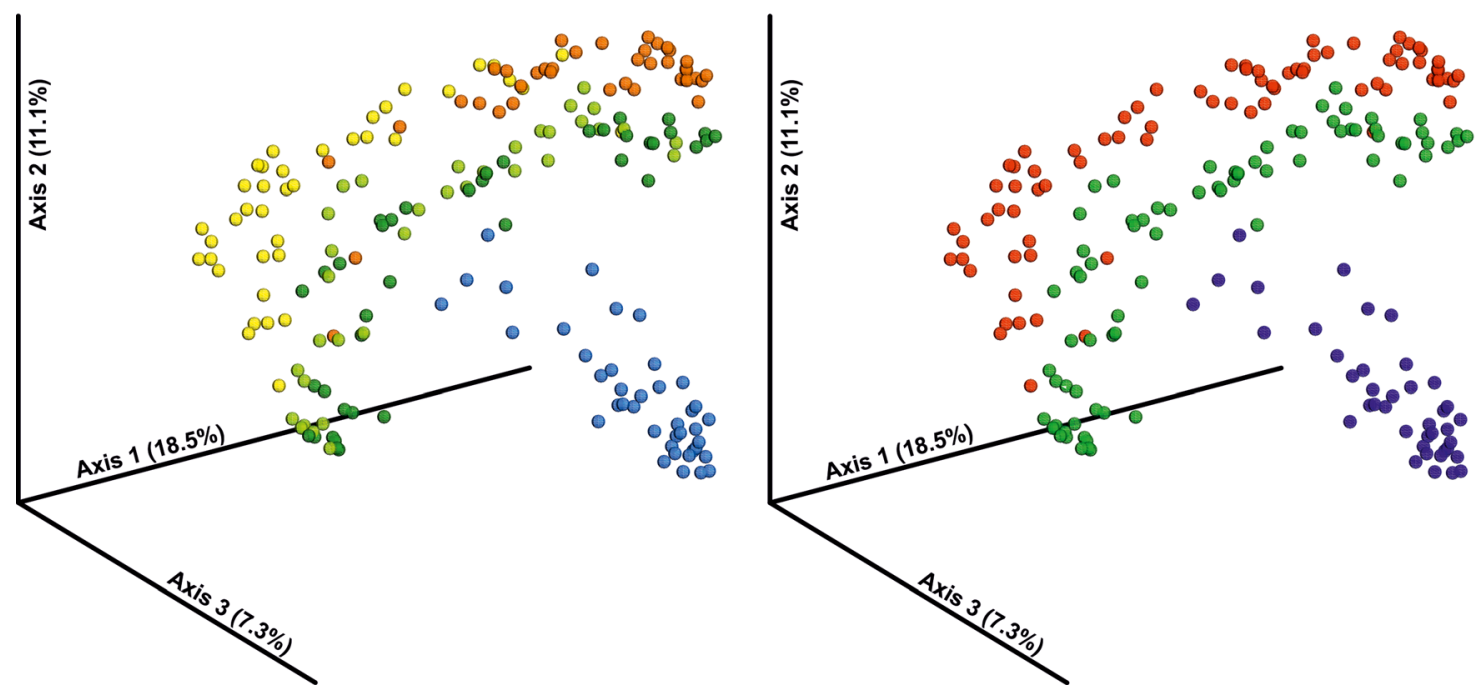

Fig. 3 Principal coordinate analyses of microbiome beta diversity metrics (Bray-Curtis distance $=$ Bray-Curtis and unweighted UniFrac $=$ uwUniFrac) presented for beetles on the level of families and trophic guilds

\section{Endosymbionts}

In total, nine taxa of endosymbiotic bacteria (including five from the male-killing group) were observed in examined beetles (Table 4). The most abundant were found to be Rickettsiales with the highest share of Wolbachia and Rickettsia. Wolbachia was the dominant bacteria (in respect to number of obtained reads among the whole microbiome) in B. punctulatum, B. varicolor, P. limnophilus, Paederus riparius, P. ruficollis, A. venustula, C. quatuordecimpunctata, A. quadrisignatus, E. ovulum, $P$. inustus, A. haemorrhoidalis, O. similis, and $O$. taurus, in 13 out of 24 examined species. Three distinct OTUs were identified for Wolbachia. Their occurrence was generally host species-specific, but there are also cases in which two OTUs were present in the same species and even individual. In all such cases, one OTU over-dominating other (see Suppl. Table 1 for details).

Rickettsia was most abundant in B. decorum, B. punctulatum, P. limnophilus, C. musciformis, A. quadrisignatus, E. ovulum, and P. inustus, in 7 out of 24 examined beetles. In four species (B. punctulatum, $P$. limnophilus, E. ovulum, and $P$. inustus) both these bacteria were found in high prevalence (Table 4). Two OTUs of Rickettsia were present in analyzed beetles, and one of them was found in much higher number of reads (see Suppl. Table 1 

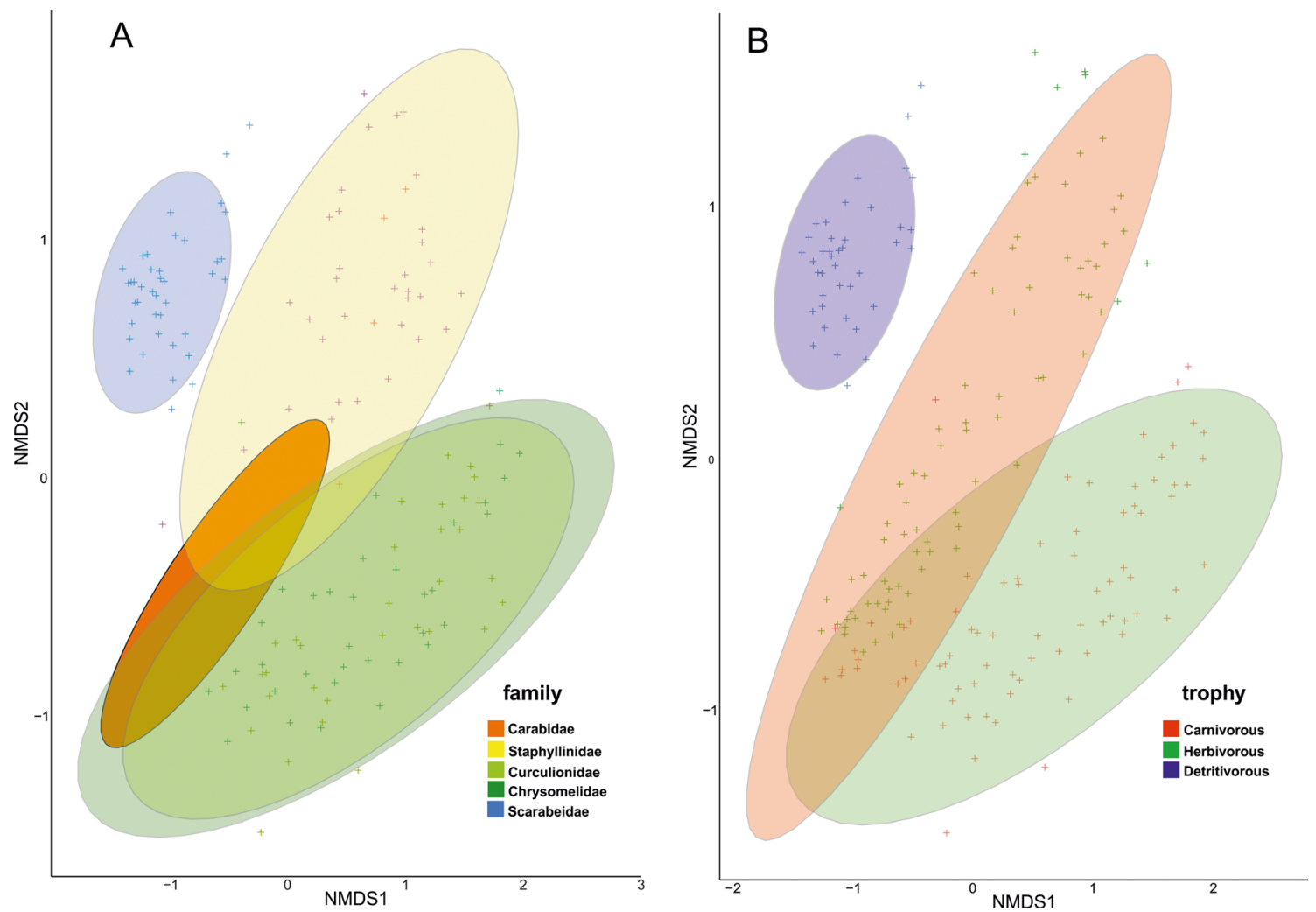

Fig. 4 Non-metric multidimensional scaling plot of Bray-Curtis dissimilarities between microbiomes found in beetle individuals belonged to particular families (a) and trophic guilds (b). Ellipses $=95 \%$ confidence intervals.

for details). Contrary to Wolbachia, cases with two OTUs present in the same species and individual were rare.

Spiroplasma found be much less numerous (in respect to Illumina reads), but it was found in quite large numbers in the following beetle hosts: $P$. limnophilus, $P$. riparius, $P$. inustus, and in lower number in, e.g., B. decorum, C. quatuordecimpunctata, A. sphacelatus (Table 4). There were four OTUs of Spiroplasma in the whole dataset, but one of these units was over-dominating and was found in the majority of beetle hosts with the exception of predatory species (see Suppl. Table 1 for details). Similarly, as in Rickettsia, there were almost no cases with multiple units present in the single species and individual.

Other six taxa of endosymbiotic bacteria, only small number of reads in single hosts were found, such as: Cardinium (in B. varicolor); Arsenophonus (in P. limnophilus); Buchnera (in A. venustula, C. duodecimpunctata, A. quadrisignatus, C. leucogrammus, E. ovulum, A. depressus, A. pusillus, O. ruficapillus); Regiella (C. duodecimpunctata, E. ovulum); Serratia (P. ruficollis, C. leucogrammus, O. ruficapillus); and Sulcia (C. quatuordecimpunctata, E. ovulum). Only for Buchnera were four OTUs identified. All other endosymbiotic bacteria were represented by a single OTU found in all infected beetles (see Suppl. Table 1 for details).

There were no significant correlations among number of reads of these endosymbiotic bacteria, with the exception of
Buchnera and Regiella (Rho $=0.45$ if consider number of reads and Rho $=0.50$ for presence/absence data) as well as Buchnera and Wolbachia (Rho $=-0.17$ only if considering number of reads). For the two most abundant endosymbiotic bacteria, i.e., Wolbachia and Rickettsia, no correlation was found ( $\mathrm{Rho}=0.04, p>0.05$ if consider number of reads and Rho $=-0.02, p>0.05$ for presence/absence data; Fig. 5a).

Regarding the endosymbiotic bacteria, their total number of reads significantly but very weakly and negatively correlated with alpha diversity of other bacteria in beetle hosts (Rho = -0.21 for OTU, Rho $=-0.18$ for Shannon, Rho $=-0.20$ for Faith, and Rho $=-0.17$ for Pielou Fig. 5b). If consider presence/absence data, significant but weak correlations were observed only between alpha diversity metrics and Rickettsia and Buchnera (e.g., Rho $=-0.29$ and 0.21 for Faith, respectively). All other endosymbiotic bacteria were not correlated with any of alpha diversity metrics.

\section{Hosts Distances vs Endosymbionts}

For three out of four alpha diversity metrics (Shannon, Faith, and Pielou), the model which was found to have the lowest AIC and highest AIC weight was that which included both explanatory variables, that is: DISTANCE and ENDOSYMBIONTS (Table 5). Only in the case of OTU, "the best" model included only DisTANCE. However, in other GLMs (with the exception 

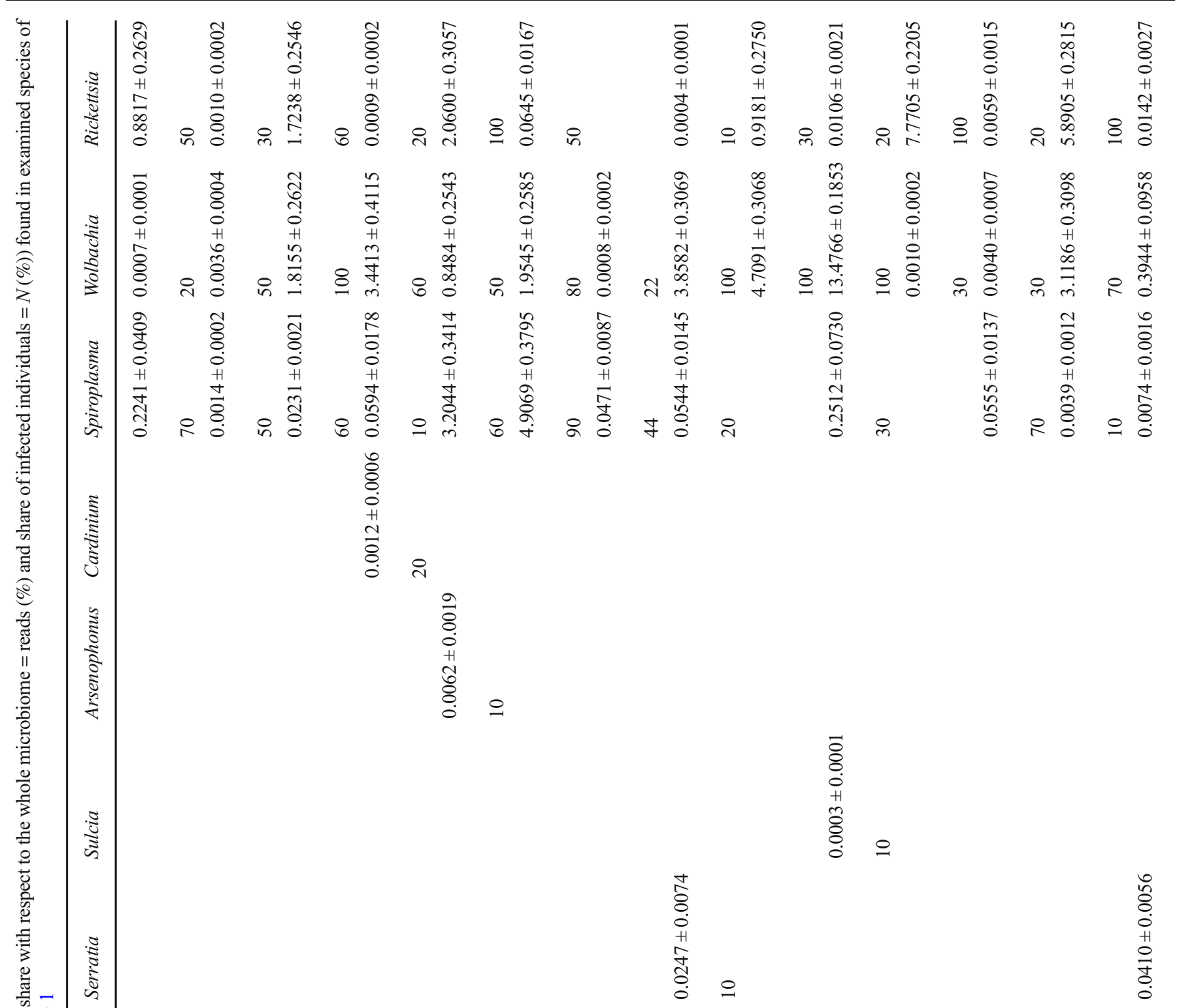

0
8
8
0
+1
0
0
0
0

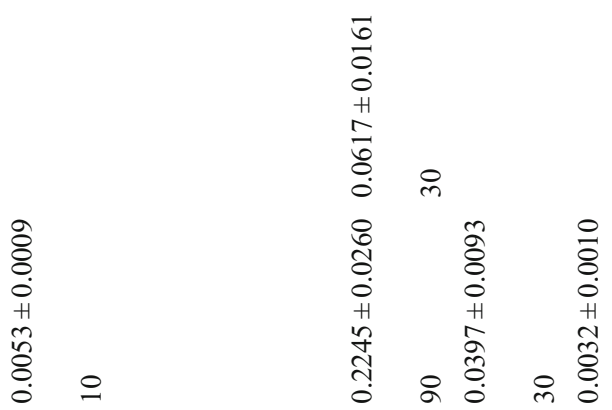

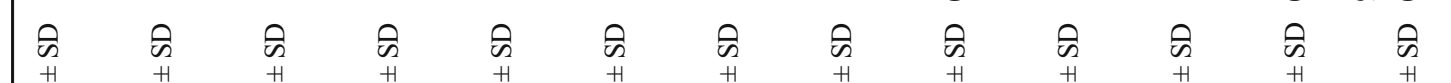

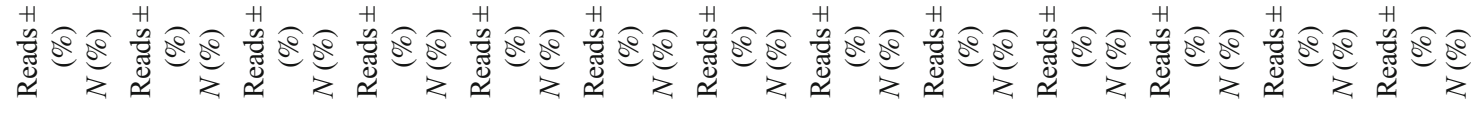




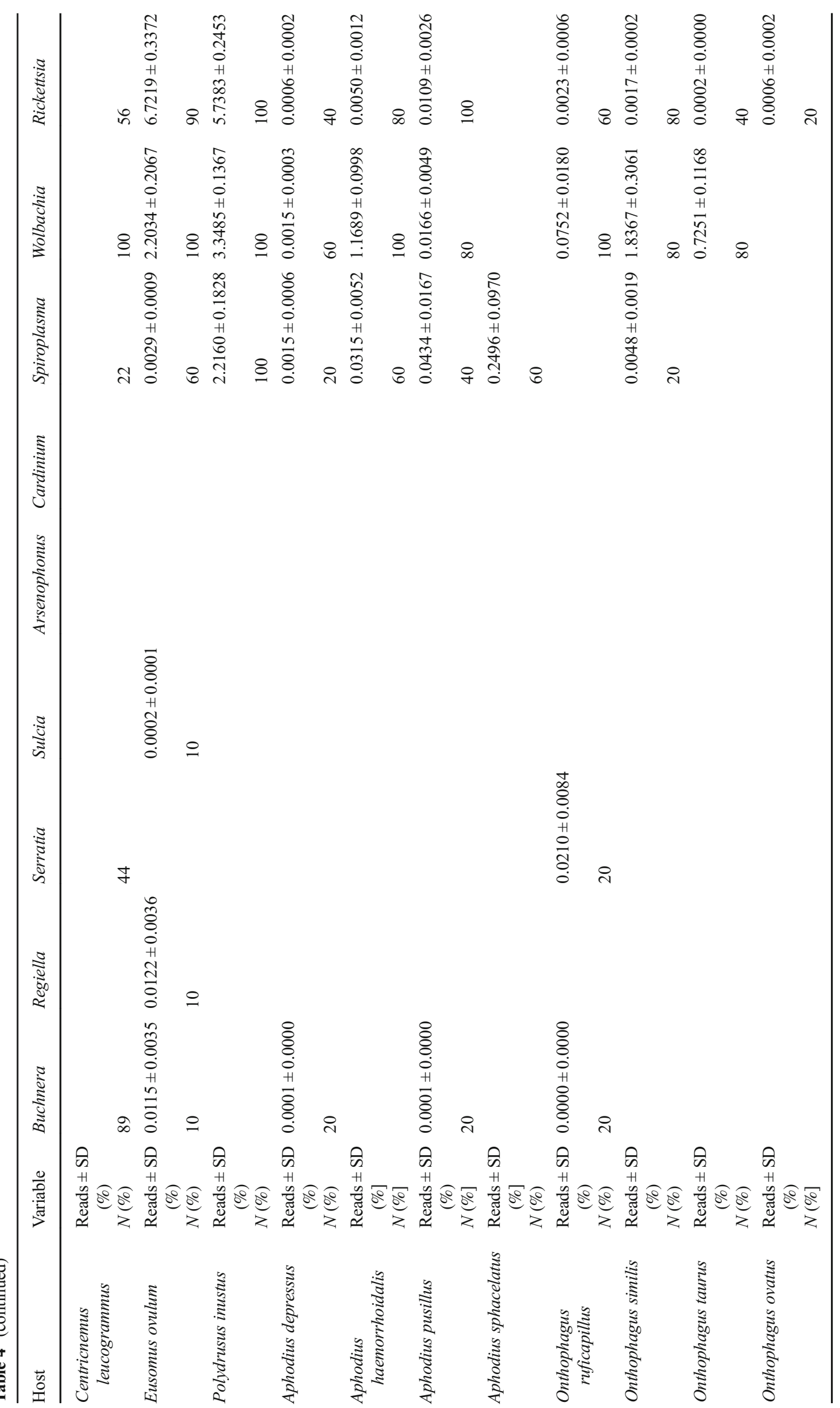


Fig. 5 Correlation between a microbiome diversity (presented on example of Faith's Phylogenetic Diversity) and endosymbiotic bacteria prevalence (numbers of Illumina reads of $16 \mathrm{~S}$ rDNA sequences) in examined beetles and $\mathbf{b}$ Wolbachia and Rickettsia prevalence
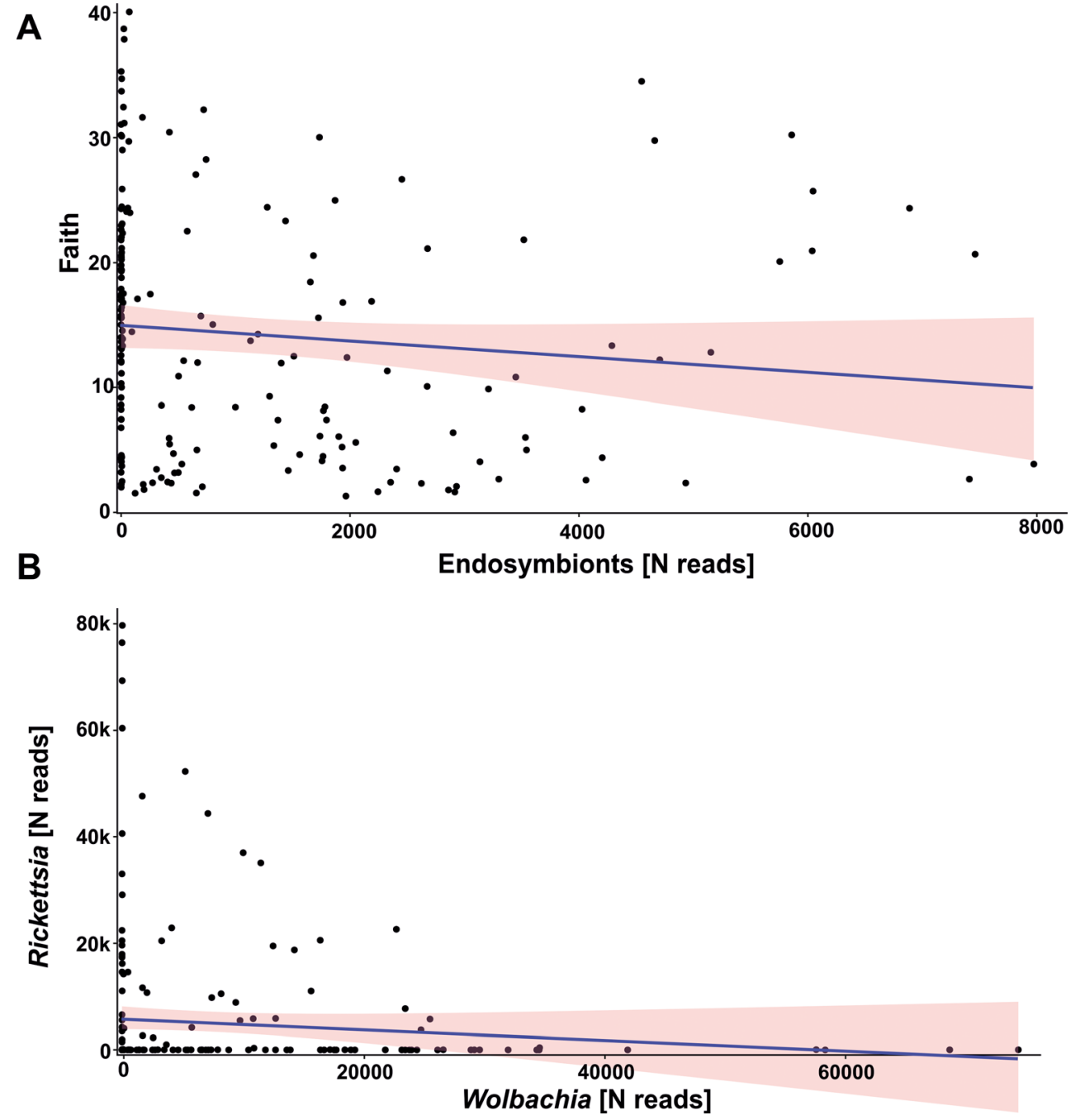

of Faith), the second model had AIC weight lower from the best model of less than 2, what according to Arnold [59] did not allow for recognizing which of these models better explained microbiome diversity. In all GLMs, the model with the lowest AIC weight included only ENDOSYMBIONTS (Table 5), what indicated that abundance of endosymbionts was a much worse explanatory of microbiome diversity than genetic distances of infected hosts.

\section{Discussion}

The most important discovery of the presented study is that microbiota communities vary greatly in insect hosts (here using beetles) and that bacteria diversity is shaped by both host phylogenetic relations (in simplicity taxonomy) and trophic affinity. The novelty of this study is that it simultaneously analyses microbiome of numerous taxa on several specimens each, whereas almost all former research [31, 33, 35] was focused on single representatives belonging to a particular taxonomic unit and trophic guild. According to a brief literature search, there are only several studies on microbiome of selected beetles (all listed in the "Introduction"). These previous studies did not allow for comparative analyses. In contrast, numerous specimens are examined in this study at the same time and conditions. They belonged to 24 selected species of beetles from five families and three trophic guilds. It also exceeds the pioneer works of Colman et al. [28] and Yun et al. [29], which were the only studies that examined microbiome diversity in respect to hosts taxonomy (for various insects) and diet preferences. However, the studies of Colman and Yun, which inspired our work, had some limitations listed above (see "Introduction"), which are overcome in the presented article.

Our results indicate that bacterial communities are highly diverse on every level of grouping. Regarding alpha diversity of bacteria found in beetle hosts, a high variability of microbiota in coleopterans was observed on all examined levels, starting from variable number of OTUs found in specimens of particular species as well as various values of diversity 
Table 5 Generalized linear models verifying which explanatory variable - cytochrome oxidase subunit I distances among infected beetles [DISTANCE] or abundance of endosymbiotic bacteria [ENDOSYMBIONTS] better explain the alpha diversity metrics of microbiome found in examined beetles

\begin{tabular}{|c|c|c|c|c|}
\hline Model & $k$ & AIC & $\Delta$ & $w$ \\
\hline \multicolumn{5}{|l|}{ OTU } \\
\hline Distance & 2 & 2229.0 & 0.00 & 0.56 \\
\hline DISTANCE + ENDOSYMBIONTS & 1 & 2229.7 & 0.62 & 0.41 \\
\hline ENDOSYMBIONTS & 1 & 2236.1 & 7.09 & 0.02 \\
\hline INTERCEPT & 1 & 2236.8 & 7.75 & 0.01 \\
\hline \multicolumn{5}{|l|}{ Shannon } \\
\hline DISTANCE + ENDOSYMBIONTS & 2 & 778.2 & 0.00 & 0.70 \\
\hline Distance & 1 & 779.9 & 1.74 & 0.30 \\
\hline ENDOSYMBIONTS & 1 & 793.8 & 15.60 & 0.00 \\
\hline INTERCEPT & 1 & 797.0 & 18.75 & 0.00 \\
\hline \multicolumn{5}{|l|}{ Faith } \\
\hline DisTANCE + ENDOSYMBIONTS & 2 & 1584.8 & 0.00 & 0.98 \\
\hline Distance & 1 & 1592.3 & 7.54 & 0.02 \\
\hline ENDOSYMBIONTS & 1 & 1628.2 & 43.39 & 0.00 \\
\hline INTERCEPT & 1 & 1642.2 & 57.39 & 0.00 \\
\hline \multicolumn{5}{|l|}{ Pielou } \\
\hline DISTANCE + ENDOSYMBIONTS & 2 & 6.1 & 0.00 & 0.72 \\
\hline Distance & 1 & 8.0 & 1.84 & 0.28 \\
\hline ENDOSYMBIONTS & 1 & 23.0 & 16.84 & 0.00 \\
\hline INTERCEPT & 1 & 26.6 & 20.50 & 0.00 \\
\hline
\end{tabular}

metrics on the level of families and trophic guilds. On the species level, it was interesting to detect different values of alpha diversity metrics even between closely related species (from the same genera), which share habitats and diet. Such a situation was observed for four Bembidion ground beetles (e.g., $B$. decorum has on average 2.5 times more diverse microbiome than B. modestum), Aphodius dung beetles (e.g., $A$. depressus has on average eight times more diverse microbiome than A. sphacelatus), and Onthophagus dung beetles (e.g., $O$. taurus has on average four times more diverse microbiome than $O$. ovatus). The most pronounced example is two sister Crioceris leaf-beetles [60], with C. quatuordecimpunctata c. 14-fold lower bacteria diversity than C. duodecimpunctata. Kolasa et al. [48] showed that these two species differ also in terms of Wolbachia infection (C. quatuordecimpunctata totally infected, C. duodecimpunctata uninfected), despite feeding on the same host plant. As Wolbachia infection could cause decreases of bacterial diversity (see [3] for Drosophila melanogaster), the high prevalence of this endosymbiont in C. quatuordecimpunctata could explain its very low diversity of the entire microbiome. The only exception seemed to be Paederus/Paederidus rove beetles, as all four examined species share similar and low levels of microbiome diversity. These differences in bacteria diversity among particular species of beetles are not easily explained due to deficiency of other studies for comparison. Some biases caused by laboratory procedures could not be totally ruled out. However, all conditions (during DNA isolation, amplification, and sequencing) were the same for each specimen. Also, the number of examined individuals were the same within families. It could not be simply explained by different microbiota associated with species hosts, as particular individuals of beetles, even within species, often expressed by very different composition of bacteria. It is interesting that on principal coordinate analyses plots particular specimens are usually intermixed between species. Contrary to this, bar plots (showing relative abundance of bacteria across hosts) suggest that particular beetle species is dominated by one, two, or few bacterial taxa. One explanation for these results could be that it suggests that lack of distinctiveness of microbiota found in members of particular beetle species is caused by a high diversity of low-abundant bacteria. Second possibility is that these few dominating bacterial taxa could be responsible for similarities of beetle hosts if considering them on higher levels (taxonomic or trophic). The majority of beetle species were found to be infected by widespread, usually aerobic bacteria of commensal lifestyle (e.g., Enterococcus (Bacilli), Comamonadaceae (Betaproteobacteria), Enterobacteriaceae and Pseudomonas (both Gammaproteobacteria), Neisseriaceae (Betaproteobacteria) etc.). Enterococcus is a member of Firmicutes, which were found to be dominant bacteria in insect microbiomes [29]. These aerobic bacteria are most common in ground beetles and rove beetles and constitute a substantial part of microbiome in weevils and leaf beetles as well. All four of these groups of beetles are free-living and are associated with various types of fresh foods, either animals (small invertebrates in case of carnivores) or plants (green tissues in case of herbivores). It is interesting that in rove beetles, a high share of bacteria were anaerobic Flavobacteriaceae, Fusobacteria, and Clostridia, which is consistent with the lifestyle of Paederus/ Paederidus. These species occupy muddy riverbanks and live within decomposing remains of plants, where aerobic conditions are present. In some species of weevils, aerobic bacteria were present, which could be present on the surface of leaves of their host plants. The presence of these bacteria could be explained in light of findings of synergies in insect-microbe relationships at the interface of plant-insect defenses [39]. Dominant bacteria in many beetles were endosymbiotic taxa, which is concordant with microbiome studies of insects [29]. Wolbachia and/or Rickettsia were especially abundant among some weevils, leaf beetles, and ground beetles, whereas these microbes infected only single members of dung beetles in low frequency. The most interesting results were obtained for 
Scarabaeidae, the microbiota of which was dominated by Pseudomonadales (mainly Acinetobacter) and Carnobacterium (Bacilli). These bacteria are known from decomposing organic material (like dung or carcasses). This finding is also consistent with the diet of examined dung beetles. Other studies also supported a high prevalence of Pseudomonadaceae in dung beetles [31,32]. Moreover, some pathogenic bacteria were found in dung beetles such as Pasteurella (Gammaproteobacteria), which are known as zoonotic pathogens and most probably originated from domestic animals (cows, sheep, horses) on which dungs these beetles were collected. Also, other bacteria found mainly in dung beetles, but also in a low share in other hosts, were known as facultative pathogens (e.g., Pantoea, Empedobacter, Enterococcus and others); unfortunately, the only studies which describe their pathogenesis concern vertebrates (e.g., $[61,62]$ ) and data for invertebrates are missing (it is uncertain if only some insects could serves as vectors for these bacteria or could also suffer from their pathogenesis). The aforementioned description of bacteria living in beetles also explains the high dissimilarity between microbiome beta diversity metrics assessed for particular hosts. Despite a great variation of microbiome diversity within species, species from particular families or trophic guilds expressed much greater distinctiveness in their bacterial communities. Various compositions of bacteria in beetle species also causes significant differences if analyzing beetles on higher organization levels. The highest bacteria alpha diversity was found among members of Carabidae and Scarabaeidae; the lowest, among species of Staphylinidae. Simultaneously, all five examined families of beetles possessed substantially dissimilar microbiota (which is expressed by significant differences in beta diversity metrics among these groups). Similar conclusions - that insect bacterial communities are shaped by host taxonomy - were presented by Colman et al. [28] and Yun et al. [29].

An even bigger association between microbiome and trophic affinity was observed with regard to host diets. Principal coordinate analyses and non-metric multi-dimensional scaling plots showed that members of all three examined trophic guilds (carnivores, herbivores, and detritivores) form distinct units with respect to their bacterial communities. This phenomenon suggests that the trophic affinity of the host is more responsible for microbiome similarities than just host taxonomy (phylogenetic relations). Unfortunately, the sampling structure in this study (high correlation between assignment of beetle species to families and trophic guilds) prevents direct and unequivocal conclusions from being made about the role of phylogeny vs trophy. However, the observed pattern that beetles belonging to the particular trophic guild share their microbial diversity, strongly support the statement that common food resources could be mostly responsible for sharing of bacteria. This is not only consistent with the meta-analysis of insects by Colman et al. [28] and the microbiome study of insects by Yun et al. [29], but also with studies on mammals. Ley et al. [63] showed that taxonomy as well as host diet are correlated with bacterial community diversity in wild and domestic mammals (including humans). Moreover, a study by Muegge et al. [64] proved that microbial communities adapt to extremes of diet and that this is probably the case in beetles.

Indeed, endosymbiotic bacteria are one of the most significant findings of the presented work. So far, only Wolbachia has been known to infect numerous taxa of beetles (see [22] for a summary). There were also single examples of infection of Rickettsia and Spiroplasma in beetles [22, 29]. Cardinium has not been detected thus far in any beetle species [20,29]. There have been no reports about the status of Arsenophonus in beetles. Here, thanks to use of next-generation sequencing technology, we have extended the list of endosymbiotic bacteria known from beetle into eight taxa with new finding for six bacteria: Cardinium (found only in one species of ground beetle), Arsenophonus (found only in one species of ground beetle), Buchnera (found in nine hosts), Regiella (two hosts), Serratia (three hosts), and Sulcia (two hosts). All these six, newly detected bacteria were only found in very low frequencies in some individuals of particular beetle species. Therefore, it is not possible to make any conclusions about their potential effects of beetles (this is outside the scope of this article), but it is known that Buchnera and Sulcia are mutualistic, whereas Regiella and Serratia are commensalistic [65]. Cardinium and Arsenophonus, as well as Spiroplasma, Rickettsia, and Wolbachia, were considered to be either parasitic or symbiotic [65]. It is worth mentioning that all beetle species, which have been recently reported to be infected by Wolbachia with the use of traditional Sanger sequencing and multilocus sequence typing genotyping [47-49, 60, 66, 67], were also found to be infected in this study (they have a large number of Wolbachia reads in Illumina sequencing). It is interesting that the collected data reject the hypothesis that endosymbiotic bacteria from particular genera inhabits hosts interchangeably, which would explain the effect of some competition between taxa having similar effects on the hosts [68] (all these bacteria described above are transmitted transovarially [65]) and all these most abundant are known as "male-killers" [18]. Obviously, these different bacteria could live together in the same host while there are no relations among them, which could change their abundance with respect to prevalence of other bacterial taxa. The lack of a visible effect on relative abundance does not say much about other possible relations between these bacteria in multiple infected hosts. Further research is needed to investigate possible effects among various endosymbiotic bacteria, other microbes and their hosts. Another result worthy of highlighting is that this study only weakly supports the assumption that a higher abundance of endosymbionts decreases diversity of the 
whole microbiota [3]. Apparently, the association between the number of endosymbiotic bacteria and alpha diversity of other bacteria is not straightforward, and other factors could be responsible for the lower richness of bacteria in, e.g., Wolbachia- or Rickettsia-infected hosts. Also, this finding should be verified in further research. This last finding is supported by multivariate analyses, which indicates that endosymbiotic bacteria abundance is less responsible for microbiome diversity than phylogenetic relations of infected hosts (expressed by genetic distances among examined beetles).

In summary, this study rejects the hypothesis that overall on the individual level, beetles possessed more similar microbiota within species than between taxa. However, even if most beetle hosts (individuals) vary greatly, there are some beetle species, the members of which are infected by unique bacteria communities. Such communities made their host distinguishable from others. Contrary to the high intermixing of microbiota found on the individual level, there are much clearer differences of bacterial communities found in particular groups of beetles considered on higher taxonomic levels (within family). The greatest distinctiveness was observed among beetles grouped according to their trophic requirements. This finding supports the conclusions of other studies. Microbiome is shaped by both phylogenetic relations (in simplicity-taxonomy) as well as trophic affinity, and that the latter better explains differences among groups of infected hosts. Moreover, this study greatly extends knowledge about endosymbiont prevalence in Coleoptera, supporting infection by not only common Wolbachia, Rickettsia, and Spiroplasma, but also other bacteria such as Cardinium, Arsenophonus, Buchnera, Sulcia, Regiella, and Serratia. The obtained results do not support the interchangeability of endosymbiotic bacteria in beetle hosts, and suggest only weak decrease of microbiome diversity in taxa highly infected by endosymbionts.

Acknowledgements The authors are grateful to Wiesław Babik for his help in research conception design, preparation of data for analysis, and suggestions to draft of the manuscript; to Piotr Łukasik for his important comments to the draft of the manuscript; and to two anonymous reviewers for helpful comments and suggestions, which allowed for substantial improvement of the article. The authors thank two people who identified specimens of the species for some groups (Marcin Józefczyk and Łukasz Minkina). The authors kindly thank Prof. Lech Borowiec for providing the pictures of beetles from his ICONOGRAPHIA COLEOPTERORUM POLONIAE (C) Copyright by Prof. Lech Borowiec, Wrocław 2007-2018, Department of Biodiversity and Evolutionary Taxonomy, University of Wroclaw, Poland), which were used for preparing some of the graphics.

Funding This research was partially funded by the grant DEC-2013/11/ D/NZ8/00583 (Kajtoch Ł., National Science Centre, Poland) and by small grants for young researchers (Kolasa M., Polish Ministry of Science and Higher Education).
Data Accessibility Sequences produced for this study are available via the Sequence Reads Archive (https://www.ncbi.nlm.nih.gov/sra) under SRA study accessions provided in Table 1.

\section{Compliance with Ethical Standards}

No data have been fabricated or manipulated (including images) to support the conclusions. No data, text, or theories by others are presented.

Conflicts of Interest The authors declare that they have no conflict of interest. This study did not involve any protected animal species and any vertebrates. Informed consent was obtained from all individual participants included in the study.

Open Access This article is distributed under the terms of the Creative Commons Attribution 4.0 International License (http:// creativecommons.org/licenses/by/4.0/), which permits unrestricted use, distribution, and reproduction in any medium, provided you give appropriate credit to the original author(s) and the source, provide a link to the Creative Commons license, and indicate if changes were made.

\section{References}

1. McFall-Ngai M, Hadfield MG, Bosch TCG, Carey HV, DomazetLošo T, Douglas AE, Dubilier N, Eberl G, Fukami T, Gilbert SF, Hentschel U, King N, Kjelleberg S, Knoll AH, Kremer N, Mazmanian SK, Metcalf JL, Nealson K, Pierce NE, Rawls JF, Reid A, Ruby EG, Rumpho M, Sanders JG, Tautz D, Wernegreen JJ (2013) Animals in a bacterial world, a new imperative for the life sciences. PNAS 110:3229-3236. https://doi.org/10.1073/pnas. 1218525110

2. Lozupone C, Stombaugh J, Gonzalez A et al (2013) Meta-analyses of studies of the human microbiota. Genome Res 23:1704-1714. https://doi.org/10.1101/gr.151803.112

3. Shin SC, Kim S-H, You H, Kim B, Kim AC, Lee KA, Yoon JH, Ryu JH, Lee WJ (2011) Drosophila microbiome modulates host developmental and metabolic homeostasis via insulin signaling. Science 334:670-674. https://doi.org/10.1126/science.1212782

4. Everard A, Lazarevic V, Gaïa N, Johansson M, Ståhlman M, Backhed F, Delzenne NM, Schrenzel J, François P, Cani PD (2014) Microbiome of prebiotic-treated mice reveals novel targets involved in host response during obesity. ISME J 8:2116-2130. https://doi.org/10.1038/ismej.2014.45

5. Noble EE, Hsu TM, Jones RB, Fodor AA, Goran MI, Kanoski SE (2017) Early-life sugar consumption affects the rat microbiome independently of obesity. J Nutr 147:20-28. https://doi.org/10. 3945/jn.116.238816

6. Dirksen P, Marsh SA, Braker I, Heitland N, Wagner S, Nakad R, Mader S, Petersen C, Kowallik V, Rosenstiel P, Félix MA, Schulenburg H (2016) The native microbiome of the nematode Caenorhabditis elegans: gateway to a new host-microbiome model. BMC Biol 14(38):38. https://doi.org/10.1186/s12915-016-0258-1

7. Jiménez RR, Sommer S (2017) The amphibian microbiome: natural range of variation, pathogenic dysbiosis, and role in conservation. Biodivers Conserv 26:763-786. https://doi.org/10.1007/s10531016-1272-x

8. Colston TJ (2017) Gut microbiome transmission in lizards. Mol Ecol 26:972-974. https://doi.org/10.1111/mec.13987

9. Ge Y, Guo G, Ge B, Yin H, Yin H (2018) The spleen microbiota of small wild mammals reveals distinct patterns with tick-borne 
bacteria. PLoS Negl Trop Dis 12:e0006499. https://doi.org/10. 1371/journal.pntd.0006499

10. Grond K, Sandercock BK, Jumpponen A, Zeglin LH (2018) The avian gut microbiota: community, physiology and function in wild birds. J Avian Biol 49:e01788. https://doi.org/10.1111/jav.01788

11. Wang AR, Ran C, Ringø E, Zhou ZG (2018) Progress in fish gastrointestinal microbiota research. Rev Aquac 10:626-640. https:// doi.org/10.1111/raq.12191

12. Pernice M, Simpson SJ, Ponton F (2014) Towards an integrated understanding of gut microbiota using insects as model systems. J Insect Physiol 69:12-18. https://doi.org/10.1016/j.jinsphys.2014.05.016

13. Cariveau DP, Powell JE, Koch H et al (2014) Variation in gut microbial communities and its association with pathogen infection in wild bumble bees (Bombus). ISME J 8:2369-2379. https://doi. org/10.1038/ismej.2014.68

14. Audisio MC, Sabaté DC, Benítez-Ahrendts MR (2015) Effect of Lactobacillus johnsonii CRL1647 on different parameters of honeybee colonies and bacterial populations of the bee gut. Benefic Microbes 6:687-695. https://doi.org/10.3920/BM2014.0155

15. Ye YH, Seleznev A, Flores HA, Woolfit M, McGraw EA (2017) Gut microbiota in Drosophila melanogaster interacts with Wolbachia but does not contribute to Wolbachia-mediated antiviral protection. J Invertebr Pathol 143:18-25. https://doi.org/10.1016/j. jip.2016.11.011

16. Dale C, Moran NA (2006) Molecular interactions between bacterial symbionts and their hosts. Cell 126:453-465. https://doi.org/10. 1016/j.cell.2006.07.014

17. Schmid-Hempel P (2011) Evolutionary parasitology. The integrated study of infections, immunology, ecology, and genetics. Oxford University Press, Oxford

18. Hurst GD, Jiggins FM (2000) Male-killing bacteria in insects: mechanisms, incidence, and implications. Emerg Infect Dis 6: 329-336. https://doi.org/10.3201/eid0604.000402

19. Bové JM (1997) Spiroplasmas: infectious agents of plants, arthropods and vertebrates. Wien Klin Wochenschr 109:604-612

20. Zchori-Fein E, Perlman SJ (2004) Distribution of the bacterial symbiont Cardinium in arthropods. Mol Ecol 13:2009-2016

21. Caspi-Fluger A, Inbar M, Mozes-Daube N, Mouton L, Hunter MS, Zchori-Fein E (2011) Rickettsia 'in'and 'out': two different localization patterns of a bacterial symbiont in the same insect species. PLoS One 6:e21096

22. Kajtoch $Ł$, Kotásková N (2018) Current state of knowledge on Wolbachia infection among Coleoptera: a systematic review. PeerJ 6:e4471. https://doi.org/10.7717/peerj.4471

23. Taylor MJ, Hoerauf A (1999) Wolbachia bacteria of filarial nematodes. Parasitol Today 15:437-442. https://doi.org/10.1016/S01694758(99)01533-1

24. Werren JH, Windsor DM (2000) Wolbachia infection frequencies in insects: evidence of a global equilibrium? Proc R Soc Lond B Biol Sci 267:1277-1285. https://doi.org/10.1098/rspb.2000.1139

25. Perlman SJ, Hunter MS, Zchori-Fein E (2006) The emerging diversity of Rickettsia. Proc R Soc Lond B Biol Sci 273:2097-2106

26. Duron O, Bouchon D, Boutin S, Bellamy L, Zhou L, Engelstädter J, Hurst GD (2008) The diversity of reproductive parasites among arthropods: Wolbachia do not walk alone. BMC Biol 6:27

27. Hosokawa T, Koga R, Kikuchi Y, Meng XY, Fukatsu T (2010) Wolbachia as a bacteriocyte-associated nutritional mutualist. Proc Natl Acad Sci U S A 107:769-774

28. Colman DR, Toolson EC, Takacs-Vesbach CD (2012) Do diet and taxonomy influence insect gut bacterial communities? Mol Ecol 21: 5124-5137. https://doi.org/10.1111/j.1365-294X.2012.05752.x

29. Yun J-H, Roh SW, Whon TW, Jung MJ, Kim MS, Park DS, Yoon C, Nam YD, Kim YJ, Choi JH, Kim JY, Shin NR, Kim SH, Lee WJ, Bae JW (2014) Insect gut bacterial diversity determined by environmental habitat, diet, developmental stage, and phylogeny of host. Appl Environ Microbiol 80:5254-5264. https://doi.org/10. 1128/AEM.01226-14

30. Ślipinski S, Leschen R, Lawrence J (2011) Order Coleoptera Linnaeus, 1758. Animal biodiversity: an outline of higher-level classification and survey of taxonomic richness. Zootaxa 3148: 203-208

31. Estes AM, Hearn DJ, Snell-Rood EC, Feindler M, Feeser K, Abebe T, Dunning Hotopp JC, Moczek AP (2013) Brood ball-mediated transmission of microbiome members in the dung beetle, Onthophagus taurus (Coleoptera: Scarabaeidae). PLoS One 8: e79061

32. Hammer TJ, Fierer N, Bess H et al (2016) Treating cattle with antibiotics affects greenhouse gas emissions, and microbiota in dung and dung beetles. Proc R Soc Lond B Biol Sci 283: 20160150. https://doi.org/10.1098/rspb.2016.0150

33. Kaltenpoth M, Steiger S (2014) Unearthing carrion beetles' microbiome: characterization of bacterial and fungal hindgut communities across the Silphidae. Mol Ecol 23:1251-1267

34. Adams AS, Aylward FO, Adams SM, Erbilgin N, Aukema BH, Currie CR, Suen G, Raffa KF (2013) Mountain pine beetles colonizing historical and naive host trees are associated with a bacterial community highly enriched in genes contributing to terpene metabolism. Appl Environ Microbiol 79:3468-3475

35. Montagna M, Chouaia B, Mazza G, Prosdocimi EM, Crotti E, Mereghetti V, Vacchini V, Giorgi A, de Biase A, Longo S, Cervo R, Lozzia GC, Alma A, Bandi C, Daffonchio D (2015) Effects of the diet on the microbiota of the red palm weevil (Coleoptera: Dryophthoridae). PLoS One 10:e117439. https://doi.org/10. 1371/journal.pone.0117439

36. Xu L, Deng J, Zhou F, Cheng C, Zhang L, Zhang J, Lu M (2018) Gut microbiota in an invasive bark beetle infected by a pathogenic fungus accelerates beetle mortality. J Pest Sci 92:343-351. https:// doi.org/10.1007/s10340-018-0999-4

37. Berasategui A, Axelsson K, Nordlander G, Schmidt A, BorgKarlson AK, Gershenzon J, Terenius O, Kaltenpoth M (2016) The gut microbiota of the pine weevil is similar across Europe and resembles that of other conifer-feeding beetles. Mol Ecol 25: 4014-4031. https://doi.org/10.1111/mec.13702

38. Scully ED, Geib SM, Carlson JE, Tien M, McKenna D, Hoover K (2014) Functional genomics and microbiome profiling of the Asian longhorned beetle (Anoplophora glabripennis) reveal insights into the digestive physiology and nutritional ecology of wood feeding beetles. BMC Genomics 15:1096

39. Casteel CL, Hansen AK (2014) Evaluating insect-microbiomes at the plant-insect interface. J Chem Ecol 40:836-847

40. Ceja-Navarro JA, Vega FE, Karaoz U, Hao Z, Jenkins S, Lim HC, Kosina P, Infante F, Northen TR, Brodie EL (2015) Gut microbiota mediate caffeine detoxification in the primary insect pest of coffee. Nat Commun 6(7618):7618. https://doi.org/10.1038/ncomms8618

41. White JA, Richards NK, Laugraud A, Saeed A, Curry MM, McNeill MR (2015) Endosymbiotic candidates for parasitoid defense in exotic and native New Zealand weevils. Microb Ecol 70: 274-286

42. Perlatti B, Luiz AL, Prieto EL, Fernandes JB, da Silva MFGF, Ferreira D, Costa EN, Boiça Júnior AL, Forim MR (2017) MALDI-TOF MS identification of microbiota associated with pest insect Diabrotica speciosa. Agric For Entomol 19:408-417. https:// doi.org/10.1111/afe.12220

43. Klimaszewski J, Morency M-J, Labrie P, Seguin A, Langor D, Work T, Bourdon C, Thiffault E, Pare D, Newton A, Thayer M (2013) Molecular and microscopic analysis of the gut contents of abundant rove beetle species (Coleoptera, Staphylinidae) in the boreal balsam fir forest of Quebec, Canada. Zookeys 353:1-24. https://doi.org/10.3897/zookeys.353.5991

44. Tiede J, Scherber C, Mutschler J, McMahon KD, Gratton C (2017) Gut microbiomes of mobile predators vary with landscape context 
and species identity. Ecol Evol 7:8545-8557. https://doi.org/10. 1002/ece3.3390

45. Dudek K, Humińska K, Wojciechowicz J, Tryjanowski P (2017) Metagenomic survey of bacteria associated with the invasive ladybird Harmonia axyridis (Coleoptera: Coccinellidae). Eur J Entomol 114:312-316

46. Baldo L, Hotopp JCD, Jolley KA et al (2006) Multilocus sequence typing system for the endosymbiont Wolbachia pipientis. Appl Environ Microbiol 72:7098-7110. https://doi.org/10.1128/AEM. 00731-06

47. Lachowska D, Kajtoch Ł, Knutelski S (2010) Occurrence of Wolbachia in central European weevils: correlations with host systematics, ecology, and biology. Entomol Exp Appl 135:105-118. https://doi.org/10.1111/j.1570-7458.2010.00974.x

48. Kolasa M, Montagna M, Mereghetti V, Kubisz D, Mazur MA, Kajtoch $€$ (2017) Preliminary evidence of the horizontal transmission of Wolbachia between Crioceris leaf beetles (Coleoptera: Chrysomelidae) and their Asparagus host plants. Eur J Entomol 114:446-454

49. Kolasa M, Kubisz D, Mazur MA, Ścibior R, Kajtoch Ł (2018) Wolbachia prevalence and diversity in selected riverine predatory beetles (Bembidiini and Paederini). B Insectol 71:193-200

50. Kajtoch $\succeq$, Kolasa M, Kubisz D, Gutowski JM, Ścibior R, Mazur MA, Holecová M (2019) Using host species traits to understand the Wolbachia infection distribution across terrestrial beetles. Sci Rep 9:847. https://doi.org/10.1038/s41598-018-38155-5

51. Apprill A, McNally S, Parsons R, Weber L (2015) Minor revision to V4 region SSU rRNA 806R gene primer greatly increases detection of SAR11 bacterioplankton. Aquat Microb Ecol 75:129-137

52. Leek JT, Scharpf RB, Bravo HC, Simcha D, Langmead B, Johnson WE, Geman D, Baggerly K, Irizarry RA (2010) Tackling the widespread and critical impact of batch effects in high-throughput data. Nat Rev Genet 11:733-739. https://doi.org/10.1038/nrg2825

53. Caporaso JG, Kuczynski J, Stombaugh J, Bittinger K, Bushman FD, Costello EK, Fierer N, Peña AG, Goodrich JK, Gordon JI, Huttley GA, Kelley ST, Knights D, Koenig JE, Ley RE, Lozupone CA, McDonald D, Muegge BD, Pirrung M, Reeder J, Sevinsky JR, Turnbaugh PJ, Walters WA, Widmann J, Yatsunenko T, Zaneveld J, Knight R (2010) QIIME allows analysis of highthroughput community sequencing data. Nat Methods 7:335-336

54. Kruskal JB (1964) Nonmetric multidimensional scaling: a numerical method. Psychometrika 29:115-129. https://doi.org/10.1007/ BF02289694

55. Clarke KR (1993) Non-parametric multivariate analyses of changes in community structure. Aust J Ecol 18:117-143. https://doi.org/10. 1111/j.1442-9993.1993.tb00438.x

56. Kimura M (1980) A simple method for estimating evolutionary rates of base substitutions through comparative studies of nucleotide sequences. J Mol Evol 16:111-120. https://doi.org/10.1007/ BF01731581
57. Burnham KP, Anderson DR (2004) Multimodel inference: understanding AIC and BIC in model selection. Sociol Methods Res 33: 261-304. https://doi.org/10.1177/0049124104268644

58. R Development Core Team (2017) R: A language and environment for statistical computing. R Foundation for Statistical Computing, Vienna, Austria

59. Arnold TW (2010) Uninformative parameters and model selection using Akaike's information criterion. J Wildl Manag 74:11751178. https://doi.org/10.2193/2009-367

60. Kubisz D, Kajtoch Ł, Mazur MA, Lis A, Holecová M (2012) Conservation genetics of highly isolated populations of the xerothermic beetle Crioceris quatuordecimpunctata (Chrysomelidae). Invertebr Biol 131:333-344. https://doi.org/10.1111/j.1744-7410. 2012.00276.x

61. Murray BE (1990) The life and times of the Enterococcus. Clin Microbiol Rev 3:46-65. https://doi.org/10.1128/CMR.3.1.46

62. De Maayer P, Chan WY, Rubagotti E et al (2014) Analysis of the Pantoea ananatis pan-genome reveals factors underlying its ability to colonize and interact with plant, insect and vertebrate hosts. BMC Genomics 15:1

63. Ley RE, Hamady M, Lozupone C, Turnbaugh PJ, Ramey RR, Bircher JS, Schlegel ML, Tucker TA, Schrenzel MD, Knight R, Gordon JI (2008) Evolution of mammals and their gut microbes. Science 320:1647-1651. https://doi.org/10.1126/science.1155725

64. Muegge BD, Kuczynski J, Knights D, Clemente JC, Gonzalez A, Fontana L, Henrissat B, Knight R, Gordon JI (2011) Diet drives convergence in gut microbiome functions across mammalian phylogeny and within humans. Science 332:970-974. https://doi.org/ 10.1126/science. 1198719

65. Kikuchi Y (2009) Endosymbiotic bacteria in insects: their diversity and culturability. Microbes Environ 24:195-204. https://doi.org/10. 1264/jsme2.ME09140S

66. Mazur MA, Holecová M, Lachowska-Cierlik D, Lis A, Kubisz D, Kajtoch $\_$(2016) Selective sweep of Wolbachia and parthenogenetic host genomes - the example of the weevil Eusomus ovulum. Insect Mol Biol 25:701-711

67. Kotásková N, Kolasa M, Kajtoch Ł (2018) Contrasting patterns of molecular diversity and Wolbachia infection in bisexual and parthenogenetic Strophosoma weevils (Coleoptera: Curculionidae). Entomol Sci 21:385-395. https://doi.org/10.1111/ens.12317

68. McLean AHC, Parker BJ, Hrček J et al (2018) Consequences of symbiont co-infections for insect host phenotypes. J Anim Ecol 87: 478-488. https://doi.org/10.1111/1365-2656.12705

The manuscript has not been submitted to any other journal for simultaneous consideration and has not been published previously (partly or in full). This single study is not split up into several parts. 